\title{
The Insula Cortex Contacts Distinct Output Streams of the Central Amygdala
}

\author{
Marion Ponserre, ${ }^{1 *}$ Christian Peters, ${ }^{1 *}$ Federica Fermani, ${ }^{1}$ Karl-Klaus Conzelmann, ${ }^{2}$ and Rüdiger Klein ${ }^{1}$ \\ ${ }^{1}$ Department of Molecules, Signaling, Development, Max-Planck Institute of Neurobiology, Martinsried 82152, Germany, and ${ }^{2}$ Max von \\ Pettenkofer-Institute and Gene Center, Ludwig-Maximilians-University Munich, Munich 81377, Germany
}

The emergence of genetic tools has provided new means of mapping functionality in central amygdala (CeA) neuron populations based on their molecular profiles, response properties, and importantly, connectivity patterns. While abundant evidence indicates that neuronal signals arrive in the CeA eliciting both aversive and appetitive behaviors, our understanding of the anatomy of the underlying long-range CeA network remains fragmentary. In this study, we combine viral tracings, electrophysiological, and optogenetic approaches to establish in male mice, a wiring chart between the insula cortex (IC), a major sensory input region of the lateral and capsular part of the $\mathrm{CeA}(\mathrm{CeL} / \mathrm{C})$, and four principal output streams of this nucleus. We found that retrogradely labeled output neurons occupy discrete and likely strategic locations in the CeL/C, and that they are disproportionally controlled by the IC. We identified a direct line of connection between the IC and the lateral hypothalamus (LH), which engages numerous LH-projecting $\mathrm{CeL} / \mathrm{C}$ cells whose activity can be strongly upregulated on firing of IC neurons. In comparison, $\mathrm{CeL} / \mathrm{C}$ neurons projecting to the bed nucleus of the stria terminalis (BNST) are also frequently contacted by incoming IC axons, but the strength of this connection is weak. Our results provide a link between long-range inputs and outputs of the $\mathrm{CeA}$ and pave the way to a better understanding of how internal, external, and experience dependent information may impinge on action selection by the CeA.

Key words: central amygdala; input-output relationship; insula cortex; lateral hypothalamus; monosynaptic tracing; optogenetics

Significance Statement

Our current knowledge of the circuit organization within the central amygdala (CeA), a critical regulator of emotional states, includes independent information about its long-range efferents and afferents. We do not know how incoming sensory information is appraised and routed through the CeA to the different output channels. We address this issue by using three different techniques to investigate how a sensory region, the insula cortex (IC), connects with the motor, physiological and autonomic output centers of the CeA. We uncover a strong connection between the IC and the lateral hypothalamus (LH) with a monosynaptic relay in the CeA and shed new light on the previously described functions of IC and CeA through direct projections to the LH.

\section{Introduction}

Initially described as an output structure translating fear and appetitive memories into the correct behavioral, physiological, and autonomic signatures (LeDoux et al., 1988; Gallagher et al.,

\footnotetext{
Received Mar. 9, 2020; revised Sep. 19, 2020; accepted Sep. 22, 2020.

*M.P. and C.P. contributed equally to this work.

Author contributions: M.P. and R.K. designed research; M.P., C.P., and F.F. performed research; K.-K.C. contributed unpublished reagents/analytic tools; M.P. and C.P. analyzed data; M.P. and R.K. wrote the paper.

This work was supported by the Max-Planck Society and Deutsche Forschungsgemeinschaft Grants SPP1665 (to K.-K.C. and R.K.) and SFB870 (to K.-K.C). We thank M. Fischer, J. Cotino, and Y. Pignot for their help with management of the animal colony. We also N. Gogolla and L. Gaitanos for critically reading this manuscript and Cecilia González for graphic design assistance.

The authors declare no competing financial interests.

Correspondence should be addressed to Rüdiger Klein at rklein@neuro.mpg.de.

https://doi.org/10.1523/JNEUROSCI.0567-20.2020

Copyright $\odot 2020$ the authors
}

1990; Killcross et al., 1997; Swanson and Petrovich, 1998; Parkinson et al., 2000; Corbit and Balleine, 2005; Viviani et al., 2011), the role of the central amygdala (CeA) has recently been enriched to consist of a variety of molecularly defined cell types controlling diverse defensive and appetitive behaviors (Fadok et al., 2018). One prevailing view of the organization of microcircuits within this structure indicates that mutual inhibition between opposing cell populations allows for a rapid switch between different behavioral programs (Ciocchi et al., 2010; Haubensak et al., 2010; Li et al., 2013; Cai et al., 2014; Douglass et al., 2017; Fadok et al., 2017). In addition, CeA neurons integrate external, contextual and interoceptive inputs, independently of the lateral (LA) and basolateral (BLA) nuclei, and through microcircuit computations generate scaled outputs contingent on the current behavioral strategy and the internal 
landscape of the animal (Ehrlich et al., 2009; Veinante et al., 2013; Fadok et al., 2018).

Studies to date have probed the influence of several longrange inputs to CeA neurons on both innate and learned behaviors (Tye et al., 2011; Knobloch et al., 2012; Carter et al., 2013; Han et al., 2015; Penzo et al., 2015; Xu et al., 2016; Khalsa et al., 2018; Schiff et al., 2018; Wang et al., 2018; Gehrlach et al., 2019; Gu et al., 2020), but none have yet investigated the wiring diagram that links afferents and efferents of the CeA. The CeA is subdivided into the lateral/capsular $(\mathrm{CeL} / \mathrm{C})$ and the medial (CeM) parts, two nuclei that differ in the composition of their neuron subpopulations (Kim et al., 2017), connectivity profiles (Sah et al., 2003), and functions (Ciocchi et al., 2010; Fadok et al., 2018). Since learning processes and activity-dependent plasticity have been shown to take place in the CeL/C rather than the CeM (Ciocchi et al., 2010; Haubensak et al., 2010; Han et al., 2015; Sanford et al., 2017), we decided to focus our analysis on this subnucleus. More specifically, we investigated the synaptic connections of sensory inputs coming from the insula cortex (IC) with the main subset of $\mathrm{CeL} / \mathrm{C}$ projection neurons. Neuronal activity within the IC itself has previously been shown to be shaped by current physiological needs (Livneh et al., 2017, 2020), and direct connections from the IC to the CeA carry aversive signals (Wang et al., 2018; Gehrlach et al., 2019) that are essential in adopting an avoidance response to a cue predicting an unpleasant taste (Schiff et al., 2018). This suggests that the IC may transmit state-dependent internal and external inputs to drive adaptive behaviors and that those IC synapses onto CeA neurons may be potentiated as a result of learning-induced plasticity.

Here, we examined whether IC inputs monosynaptically target a population of local $\mathrm{CeL} / \mathrm{C}$ interneurons or populations of $\mathrm{CeL} / \mathrm{C}$ projection neurons that send direct connections to motor, physiological, or autonomic output centers. To untangle the complexity of this microcircuit, we first mapped the topographical organization of $\mathrm{CeL} / \mathrm{C}$ output neurons. We revealed a spatial pattern of cell arrangements based on their projection targets, supporting the idea that inputs to this region may be biased toward discrete output pathways. To further dissect the IC to CeL/C projection neuron connections, we employed a combination of rabies virusbased input/output tracings (TRIO; Schwarz et al., 2015) and channelrhodopsin-2 (Chr2) assisted circuit mapping (CRACM; Petreanu et al., 2007). We found that lateral hypothalamus (LH)projecting neurons receive greater inputs from the IC compared with other projection neuron types in the $\mathrm{CeL} / \mathrm{C}$. Moreover, we identified that bed nucleus of the stria terminalis (BNST)-projecting $\mathrm{CeL} / \mathrm{C}$ cells also receive substantial inputs from the IC but with weaker strength. Our investigation thus uncovers a new long-range circuit of the $\mathrm{CeA}$ and reveals how this region might channel IC input information into coordinated output responses.

\section{Materials and Methods}

\section{Animals}

WT mice were obtained from the C57BL/6NRj strain (Janvier Labs). Htr2a-Cre BAC (STOCK Tg[Htr2a-cre] KM208Gsat/Mmucd) transgenic line was obtained from the Mutant Mouse Regional Resource Center. Rosa26R44 mouse lines were as described previously (Soriano, 1999). All experiments were conducted using two- to four-month-old males. Mice used for optogenetic manipulations were handled and singly housed (on a 12/12 h light/dark cycle) for $3 \mathrm{~d}$ before photostimulation.

\section{Viral constructs}

The following AAV viruses were purchased from the University of North Carolina Vector Core (https://www.med.unc.edu/genetherapy/
Table 1. Stereotaxic coordinates from bregma

\begin{tabular}{llll}
\hline Injection site & $\begin{array}{l}\text { Rostro-caudal } \\
\text { (in mm) }\end{array}$ & $\begin{array}{l}\text { Medio-lateral } \\
\text { (in mm) }\end{array}$ & $\begin{array}{l}\text { Dorso-ventral } \\
\text { (in mm) }\end{array}$ \\
\hline pIC & -0.35 & \pm 4.05 & -4.0 \\
CeA & -1.22 & \pm 2.85 to \pm 2.9 & -4.8 \\
BNST & +0.56 & \pm 0.92 & -4.95 to -4.65 \\
PAG & -4.2 to -4.4 & \pm 0.55 & -2.84 \\
LH & -1.25 & \pm 1.15 & -5.2 \\
PBN & -5.3 & $\pm 1.35-1.45$ & -3.9 to -3.8 \\
IRN & -5.4 & \pm 1.25 & -5.6 to -4.8 \\
\hline
\end{tabular}

Rostro-caudal, medio-lateral, and dorso-ventral coordinates from bregma in millimeters for stereotaxic injections in the PIC, CeA, BNST, PAG, LH, and PBN.

vectorcore): AAV1-EF1 $\alpha$-FLEX-TVAmCherry, AAV1-CAG-FLEX-RG, AAV5-Ef1a-ChR2-eYFP, and AAV5-Ef1a-eYFP. EnvA G-deleted rabies-eGFP used for TRIO and cTRIO experiments has been previously described (Wickersham et al., 2007). We obtained the CAV2-Cre from the Montpellier Vectorology Platform of the UMS Biocampus (http:// www.igmm.cnrs.fr/en/service/adenovirus-recombinants/). HSV-hEF1 $\alpha$ Cre was supplied by the Viral Gene Transfer Core of the Massachusetts Institute of Technology (https://mcgovern.mit.edu/tile/viral-core/).

\section{Stereotaxic surgeries}

Mice were anaesthetized using isoflurane (Cp-pharma; induction, 3\%; maintenance, $1.5 \%)$ in oxygen-enriched air and head-fixed on a stereotaxic frame (Model 1900, Kopf Instruments). Body temperature was maintained at $37^{\circ} \mathrm{C}$ using a heating pad. Carprofen (rimadyl, Zoetis; $5 \mathrm{mg} / \mathrm{kg}$ body weight), and an analgesic were given via subcutaneous injection. Viral particles were delivered using glass pipettes (\#708707, BLAUBRAND intraMARK) connected to a Picospritzer III (Parker Hannifin Corporation) and controlled by a Master- 8 pulse stimulator (A.M.P.I.) at a flow rate of $50 \mathrm{nl} / \mathrm{min}$. After delivery of the virus, the pipette remained in the brain for $5 \mathrm{~min}$ to prevent spread of the virus.

For analysis of spatial segregation of CeA projection neurons, We injected $0.3 \mu \mathrm{l}$ of cholera toxin subunit B (CTB) conjugated with Alexa Fluor 488 or 555 or 647 (C34775, C34776, C34778; Invitrogen) into the BNST, and/or LH, and/or PAG, and/or PBN, and/or IRN (Table 1, stereotaxic coordinates from bregma) of WT mice. Per animal, we targeted two to three distinct output regions using CTBs of different colors. After recovery, mice were housed for $7 \mathrm{~d}$ before euthanasia.

For identification of monosynaptic inputs to BNST-, LH-, PAG-, and PBN-projecting CeA cells (TRIO experiments), 0.2-0.4 $\mu$ l of AAV1EF1 $\alpha$-FLEX-TVAmCherry and AAV1-CA-FLEX-RG mixed at a ratio of 1:4 were unilaterally or bilaterally injected into the CeA of WT mice (Table 1, stereotaxic coordinates from bregma). In the same surgery, we additionally injected $0.4 \mu \mathrm{l}$ of CAV2-Cre and HSV-hEF1 $\alpha$-Cre mixed at a ratio of 1:1 unilaterally or bilaterally in the BNST, or LH, or PAG, or PBN (Table 1, stereotaxic coordinates from bregma). Fourteen days later, mice were injected with $0.2-0.4 \mu \mathrm{l}$ of EnvA G-deleted rabies-eGFP virus into the CeA using the same exact coordinates as described above. After recovery, mice were housed for $7 \mathrm{~d}$ before euthanasia.

For ChR2-assisted circuit mapping, we injected $0.3 \mu \mathrm{l}$ of either AAV5-Ef1a-eYFP (for control experiments) or AAV5-Ef1a-ChR2-eYFP unilaterally in the pIC of WT mice (Table 1, stereotaxic coordinates from bregma). Three to four weeks later, we additionally injected $0.3 \mu \mathrm{l}$ of CTB conjugated with Alexa Fluor 647 (C34778, Invitrogen) in the BNST, and/or LH, and/or PAG, and/or PBN (Table 1, stereotaxic coordinates from bregma). In the same surgery, mice used in optogenetic experiments were unilaterally (right hemisphere) implanted with optic fibers ( $200-\mu \mathrm{m}$ core, $0.22 \mathrm{NA}, 1.25 \mathrm{~mm}$ ferrule, Thorlabs) above the CeA ( $-4.35 \mathrm{~mm}$ ventral from bregma). Implants were secured with cyanoacrylic glue, and the exposed skull was covered with dental acrylic (Paladur).

\section{Optogenetic manipulations}

Six days after injection of conjugated CTB, pIC-::ChR2-> CeA mice were unilaterally tethered to optic-fiber patch cords (Doric Lenses or 
Thorlabs) connected to a $473 \mathrm{~nm}$ CNI laser(Cobolt) via a rotary joint (Doric Lenses) and mating sleeve (Thorlabs). The photo-stimulation protocol was as follows: four sequences of $3 \mathrm{~min} \mathrm{On}(20 \mathrm{~Hz}$ and 7.5 $\mathrm{mW}$ ) and $2 \mathrm{~min}$ Off. The laser was triggered, and pulses were controlled with Bonsai data-streaming software ref and Arduino microcontrollers.

\section{Acute brain-slice preparation and electrophysiological recordings} The mice were deeply anesthetized by intraperitoneal injection of ketamine/xylazine (Medistar and Serumwerk; 100 and $16 \mathrm{mg} / \mathrm{kg}$, respectively). After decapitation, the brain was placed in ice-cold cutting solution containing the following: $30 \mathrm{~mm} \mathrm{NaCl}, 4.5 \mathrm{~mm} \mathrm{KCl}, 1 \mathrm{~mm}$ $\mathrm{MgCl}_{2}, 26 \mathrm{~mm} \mathrm{NaHCO}_{3}, 1.2 \mathrm{~mm} \mathrm{NaH}_{2} \mathrm{PO}_{4}, 10 \mathrm{~mm}$ glucose, and $194 \mathrm{~mm}$ sucrose, saturated with a mixture of $95 \% \mathrm{O}_{2}$ and $5 \% \mathrm{CO}_{2}$. After slicing the brain at a thickness of $280 \mu \mathrm{m}$ on a vibratome (Leica VT1000S), the slices were transferred to an artificial CSF (aCSF) solution containing the following: $124 \mathrm{~mm} \mathrm{NaCl}, 4.5 \mathrm{~mm} \mathrm{KCl}, 1 \mathrm{~mm} \mathrm{MgCl} 2,26 \mathrm{~mm} \mathrm{NaHCO}_{3}$, $1.2 \mathrm{~mm} \mathrm{NaH}_{2} \mathrm{PO}_{4}, 10 \mathrm{~mm}$ glucose, and $2 \mathrm{~mm} \mathrm{CaCl}_{2}$ (310-320 mOsm), saturated with $95 \% \mathrm{O}_{2} / 5 \% \mathrm{CO}_{2}$ at $30^{\circ} \mathrm{C}$ for $1 \mathrm{~h}$ before being moved to room temperature (RT). Finally, the brain slices were transferred to a recording chamber continuously perfused with aCSF solution saturated with $95 \% \mathrm{O}_{2} / 5 \% \mathrm{CO}_{2}$ at $30-32^{\circ} \mathrm{C}$.

Whole-cell patch clamp recordings from the CeA were performed on brain slices located approximately $-1.2 \mathrm{~mm}$ from bregma on a rostrocaudal axis and with a MultiClamp 700B amplifier and a Digidata 1550 digitizer (Molecular Devices). Patch pipettes were prepared from filamentcontaining borosilicate micropipettes (World Precision Instruments) using a P-1000 micropipette puller (Sutter Instruments), with a resistance of 4-6 $\mathrm{M} \Omega$. The intracellular solution for current and voltage clamp recordings contained $130 \mathrm{~mm}$ potassium gluconate, $10 \mathrm{~mm} \mathrm{KCl}, 2 \mathrm{~mm} \mathrm{MgCl}, 10 \mathrm{~mm}$ HEPES, 2 mм Na-ATP, $0.2 \mathrm{~mm} \mathrm{Na} \mathrm{NaTP}_{2} \mathrm{pH} 7.35$, and 290mOsm. Slices were visualized with a fluorescence microscope equipped with IR-DIC optics (Olympus BX51). The holding potential for voltage-clamp recordings was $-70 \mathrm{mV}$ in EPSC experiments and $0 \mathrm{mV}$ in IPSC. Data were acquired using Clampex 10.3 (Molecular Devices). Recordings were made 2-7 $\mathrm{h}$ after killing.

Data were sampled at $10 \mathrm{kHz}$, filtered at $2 \mathrm{kHz}$ and analyzed with Clampfit (Molecular Devices). For circuit mapping in brain slices, ChR2 was stimulated by light with a multi-LED array system (CoolLED) connected to the epifluorescence port of an Olympus BX51. Light pulses of $3 \mathrm{~ms}$ at $\lambda=470 \mathrm{~nm}$ ranging from 1 to $10 \mathrm{~mW} \mathrm{~mm}^{-2}$ were delivered to trigger action potentials in presynaptic axon terminals.

\section{Histology}

Animals were anesthetized with ketamine/xylazine (Medistar and Serumwerk; 100 and $16 \mathrm{mg} / \mathrm{kg}$, respectively) and transcardially perfused with phosphate-buffered saline (PBS), followed by $4 \%$ paraformaldehyde (PFA; 1004005, Merck; w/v) in PBS. Extracted brains were postfixed at $4^{\circ} \mathrm{C}$ in $4 \%$ PFA (w/v) in PBS for $12 \mathrm{~h}$, embedded in $4 \%$ agarose (\#01280, Biomol; w/v) in PBS and sliced using a Vibratome (VT1000S - Leica) into 50 - to $100-\mu \mathrm{m}$ free-floating coronal sections.

\section{Immunohistochemistry}

We incubated $50-\mu \mathrm{m}$ free-floating coronal sections in $50 \mathrm{mM} \mathrm{NH}_{4} \mathrm{Cl}$ (1.01145, Merck) for $15 \mathrm{~min}$ to reduce auto-fluorescence of the brain tissues. Sections were then permeabilized for $30 \mathrm{~min}$ at RT with $0.5 \%$ Triton X-100 (\#66831, Carl Roth) in PBS and blocked for $2 \mathrm{~h}$ at RT with $0.2 \%$ BSA (\#A7030, Sigma-Aldrich) and 5\% donkey serum (\#017-000121, Jackson ImmunoResearch; w/v) in PBS. Sections were incubated with primary antibodies in $0.2 \%$ BSA $(\mathrm{w} / \mathrm{v})$ and $0.2 \%$ Triton $\mathrm{X}-100$ in $\mathrm{PBS}$ at $4^{\circ} \mathrm{C}$ overnight. The following primary antibodies were used: mouse anti-PKC $\delta(1: 100 ; 610398$, BD Biosciences), chicken antiLacZ (1:200; ab9361, Abcam), rabbit anti-Sst (1:1000; T-4103, Peninsula Laboratories International), and donkey anti-rabbit cfos (\#2250S, Cell Signaling, dilution 1:750). Sections were washed three times $15 \mathrm{~min}$ with $\mathrm{PBS}$ and incubated $\mathrm{ON}$ at $4^{\circ} \mathrm{C}$ with secondary antibodies diluted $1: 250$ in $0.2 \%$ BSA (w/v) and $0.2 \%$ Triton X-100 in PBS. The following secondary antibodies were used: donkey antirabbit/mouse/chicken Alexa Fluor 488 or Cy3 or Alexa Fluor 647 (anti-rabbit, 711-545-152, 711-165-152, 711-495-152; anti-mouse,
715-545-151, 715-165-151, 715-605-151; anti-chicken, 703-545-155, 703-165-155, 703-605-155; Jackson ImmunoResearch). Sections were washed two times 15 min with $0.1 \%$ Triton X-100 in PBS and incubated with DAPI (1:2000; Sigma-Aldrich) in PBS. After $15 \mathrm{~min}$ wash in PBS, sections were finally coverslipped using Fluorescent Mounting Medium (\#S3023, Dako).

\section{Microscopy and image processing}

A Leica SP8 confocal microscope equipped with a $20 \times / 0.75$ IMM objective (Leica) was used to acquire Fluorescence z-stack images. Epifluorescence images were obtained with an upright epifluorescence microscope (Zeiss) with $5 \times / 0.15$ or $10 \times / 0.3$ objectives (Zeiss). Full views of CeA and surrounding nuclei were acquired using the tile scan and automated mosaic merge functions of Leica LAS AF software. Images were minimally processed with ImageJ software (NIH) to adjust for brightness and contrast for optimal representation of the data. A median filter was used to decrease noise.

\section{Data analysis}

Reconstruction in digital three-dimensional (3D) of CeL/C projection neurons and spatial segregation analysis

For analysis of spatial segregation of $\mathrm{CeL} / \mathrm{C}$ projection neurons, the $\mathrm{CeA}$ of WT mice that had been stereotaxically injected in the BNST, and/or $\mathrm{LH}$, and/or PAG, and/or PBN with CTB conjugates, were cut into 70$\mu \mathrm{m}$-thick coronal sections. For each brain, we visually inspected that CTB injections in the output regions were localized according to Allen Institute's reference atlas (Lein et al., 2007). Z-stack images of all sections from -1.1 to $-1.7 \mathrm{~mm}$ posterior to bregma were acquired.

Processing of Z-stack images and 3D reconstructions was done using Amira software (Visage Imaging). First, fluorescence intensity attenuation in the $\mathrm{z}$ direction was corrected using the Correct $\mathrm{Z}$ Drop module for each $z$-stack image. Using the Transform Editor, the spatial positions of each z-stack were then manually transformed using a combination of translations and rotations to roughly align them with respect to each other. In order to turn the initial serial images into a correct 3D model, $\mathrm{z}$-stacks were then concatenated (each channel separately), and manually aligned by translating and rotating the upper slices using the Align Slices module. Once one channel was properly aligned, the data set was resampled into a new aligned 3D image and this image was used as a reference to apply the same alignment to the other channels.

We additionally needed to compare projection neuron distributions across mice and so to register all tracing brains to one common coordinate system. For this, one traced brain was chosen as a reference and the other ones were registered to the reference brain using the Register Images module. First, the $\mathrm{CeL} / \mathrm{C}$ of each traced brain was manually segmented using the Segmentation Editor based on Paxinos and Franklin's atlas (Paxinos and Franklin, 2001), and all segmented CeAs were saved as labels. In the Register Images module, we then used the CeA label of the chosen traced brain as a reference and the option: Label Difference as a metric. All transformations were rigid.

We additionally rotated all registered datasets (using the Transform Editor) in the same angle so that the $x$-axis corresponded to the lateralmedial axis, the $y$-axis to the dorso-ventral axis, and the $z$-axis to the rostro-caudal axis of the brain. Retrogradely labeled cell bodies were reconstructed using the Interactive Thresholding module and the corresponding segmented CeA labels as masks.

Cell bodies inferior to $12 \mu \mathrm{m}$ in diameter on the $\mathrm{x}$ and $\mathrm{y}$ axes were discarded using the Remove Small Spots module. Finally, digital coordinates along the $x$-, $y$-, and $z$-axes of reconstructed cell bodies were extracted using the Measure and Analyse, Individual measures, Label analyses, and Basic modules.

Colocalization of BNST-projecting and LH-projecting cells with PKC $\delta$, SST, and Htr2a markers

We analyzed three to four sections per animal that covered the CeA from anterior to posterior. The total number of CTB-positive and double-positive cells were quantified. For each brain, we visually inspected that viral infection in the pIC as well as CTB injection in the output 
regions were localized according to Allen Institute's reference atlas (Lein et al., 2007).

Identification of IC inputs to BNST-projecting, LH-projecting, PAG-projecting, and PBN-projecting CeA cells (TRIO experiments)

For quantification of starter cells in the CeL/C and CeM, every section or every second section from -0.9 to $-1.8 \mathrm{~mm}$ posterior to bregma was quantified with ImageJ (NIH) based on Paxinos and Franklin's atlas (Paxinos and Franklin, 2001). A small number of starter neurons were found in the neighbouring nuclei namely globus pallidus (GP), caudate putamen $(\mathrm{CP})$, substantia innominata $(\mathrm{SI})$, medial amygdala $(\mathrm{MeA})$, and the very lateral part of the LH but were not quantified as they accounted for a small portion of the total starter populations. Only brains that showed a high tracing efficiency and the presence of a large number of starter cells in the CeL/C were chosen for analysis. We also paid attention to only compare animals with similar number of starter cells in the $\mathrm{CeL} / \mathrm{C}$ between different experimental conditions.

For quantifications within the IC (boundaries according to the Allen Institute's reference atlas; Lein et al., 2007), every section was quantified, but only the input neurons ipsilateral to the injection site were considered. The total number of RABV-eGFP was manually scored.

\section{c-Fos quantifications}

We analyzed four sections per animal of $12 \mu \mathrm{m}$ that covered the CeA from anterior to posterior. The total number of c-Fos-positive, CTB-positive and double-positive cells were quantified. For each brain, we visually inspected that viral infection in the pIC as well as CTB injection in the output regions were localized according to Allen Institute's reference atlas (Lein et al., 2007). We always made sure that our viral injections in the pIC did not spread in the BLA, however depending on the animal, the anterior and medial part of the IC were more or less infected. As previously reported (Gehrlach et al., 2019) strong eYFP axonal fibers were visible in the CeA only when the posterior part was sufficiently infected.

Electrophysiological recordings

Recordings were analyzed using Clampfit (Molecular Devices) and Prism (GraphPad).

\section{Statistical analysis}

No statistical methods were used to predetermine sample sizes. The numbers of samples in each group were based on those in previously published studies. Frequency distributions, smoothed curves, as well as linear and nonlinear least squares (Gaussian) regression fitting were performed using GraphPad Prism (GraphPad). Raw data were smoothed by averaging two neighboring points and fitting the curve to a second order polynomial. $2 \mathrm{D}$ kernel density estimations were used to estimate the probability density functions of LH-projecting, PAG-projecting, and $\mathrm{PBN}$-projecting neurons location along the $\mathrm{x}$ - and $y$-axes and were created in R (http://www.r-project.org/) using the "kde2d" function provided in the "MASS" library. Bandwidths in the density estimation were chosen using the "bandwidth.nrd" function. Estimates were graphically displayed as contour plots, with the contour lines connecting points of equal probability density and drawn for probability density values between $10 \%$ and $70 \%$ of the probability density in step of $20 \%$. Pairwise comparisons were calculated with unpaired two-tailed $t$ tests and performed in GraphPad Prism. Significance levels are indicated as follows: $* p<0.05, * * p<0.01, * * * p<0.001$. After the conclusion of experiments, the location of the CTB injections, virus-expression and opticfiber placements were verified.

\section{Results}

\section{Spatial organization and firing properties of $\mathrm{CeL} / \mathrm{C}$ projection neurons}

To visualize the relative proportions and spatial organization of CeA output neurons, we injected retrogradely transported CTB conjugated with different fluorescent molecules into the major output regions of the CeA (Sah et al., 2003), namely the BNST, $\mathrm{LH}$, ventro-lateral periaqueductal gray (vlPAG), parabrachial nucleus $(\mathrm{PBN})$, paraventricular nucleus of the thalamus (PVT), and intermediate reticular nucleus (IRN; Fig. 1A,B; Table 1). We found that projections to the BNST, LH, PAG, and PBN originated from both the CeL/C and the CeM (Fig. $1 C, D$ ), while the IRN was innervated by CeM cells only (Fig. $1 E$ ); we failed to identify retrogradely labeled cells in the whole CeA after CTB injections in the PVT (data not shown). Since IC axons preferentially innervate the CeL/C rather than the CeM (Shi and Cassell, 1998; McDonald et al., 1999), we decided to focus our analysis on CeL/ $\mathrm{C}$ subpopulations innervating the BNST, LH, PAG, or PBN. We assigned $x-y-z$ coordinates to labeled projection neurons (Fig. $1 D$ ) and extracted 3D distributions. All four projection types showed an even distribution along the rostro-caudal dimension (Fig. 1F). Conversely, spatial differences were observed between cells projecting to the LH and PAG and PBN-projecting neurons, with LHprojecting and PAG-projecting cells exhibiting a ventral-medial profile while $\mathrm{PBN}$-projecting neurons populated the dorso-lateral part of the CeL/C (Fig. 1G-J). Among the four projection types, BNST-projecting cells populated the whole nucleus most uniformly (Fig. 1F-H).

Our quantifications revealed that the greatest number of CTB-labeled cells projected to the BNST, followed by the PBN, $\mathrm{LH}$, and PAG (Fig. $1 \mathrm{~K}$ ). Among the four target regions, the $\mathrm{BNST}$ is located closest to the $\mathrm{CeL} / \mathrm{C}$ raising the possibility that these numbers primarily reflect distance traveled by the tracer. On the other hand, the PBN is located furthest away, and the number of PBN projectors was the second highest in our analysis. Thus, we suggest that the observed cell distributions were not caused by differences in labeling efficiency because of distinct axon lengths, but approximately reflect the real proportions of these projection neurons within the $\mathrm{CeL} / \mathrm{C}$.

Additionally, we examined the electrophysiological properties of the CTB-labeled cells in acute amygdala slices. Because of their low spontaneous activity, spiking was evoked by the injection of depolarizing current steps (Fig. $2 A-D$ ). The results revealed two major types of neurons, late-firing and regular-spiking neurons, as previously described (Chieng et al., 2006; Haubensak et al., 2010; Douglass et al., 2017; Hunt et al., 2017). This is determined by the firing delay observed from the start of the current injection to the beginning of the first action potential induced by the depolarizing current injection step. The data analysis showed that BNST-projecting and PAG-projecting cells were homogeneous populations of regular-firing neurons (Fig. 2A,C,E), LH-projecting cells were mostly regular-firing neurons with some cells displaying delayed onset (Fig. $2 B, E$ ), while PBN-projecting neurons exhibited a range of regular- to late-firing properties (Fig. $2 D, E)$.

It was previously shown that efferents to the PAG and PBN originate from somatostatin (SOM or Sst)-expressing cells that partially encompass Htr2a, Crh, Tac2, and Nts, but not PKC $\delta$ positive neurons (Magableh and Lundy, 2014; Penzo et al., 2014; Douglass et al., 2017; Kim et al., 2017; Ye and Veinante, 2019). We further assessed the molecular identities of BNST-projecting and LH-projecting populations and found that BNST-projecting neurons mostly emanated from $\mathrm{PKC} \delta+$ cells, with small contributions from Htr $2 \mathrm{a}+$ and Sst + cells $(50.9 \pm 3.3 \%$ of CTB + cells were immunopositive for $\mathrm{PKC} \delta$ while only $6.3 \pm 3.3 \%$ and $5.9 \pm 0.6 \%$ of CTB + cells were immunopositive for Htr2a-LacZ and Sst proteins, respectively; Fig. 2F,G). The remaining 35-40\% unlabeled $\mathrm{CTB}+$ neurons may belong to the subpopulation marked by Tac2/Nts/Crh (Kim et al., 2017). Conversely, LH-projecting neurons derived from all three subpopulations with Sst+ and Htr2a + neurons being slightly more represented than 
A

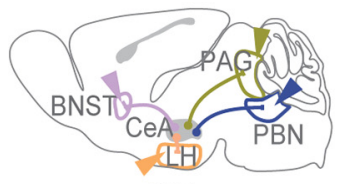

WT

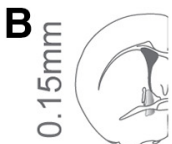

CTB BNST

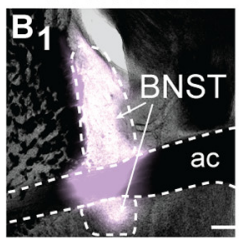

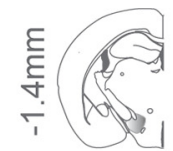

CTB LH

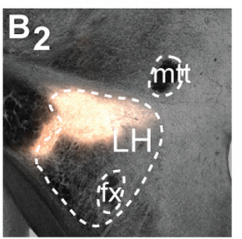

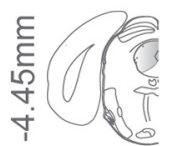

CTB PAG

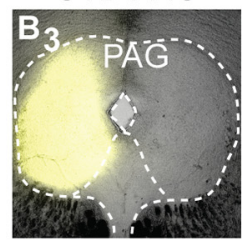

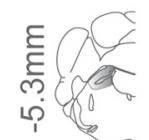

CTB PBN

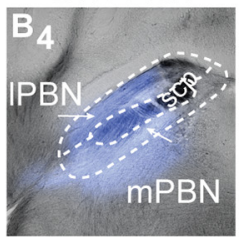

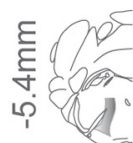

CTB IRN

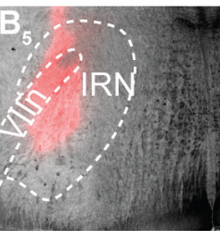

C CTB BNST

CTB LH

CTB PAG

CTB PBN

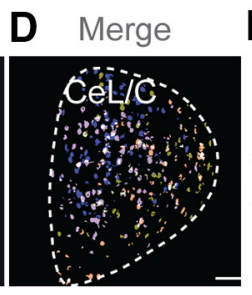

E
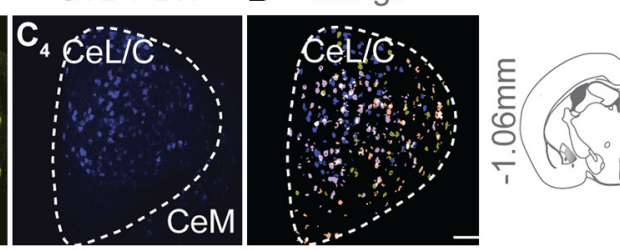

CTB IRN
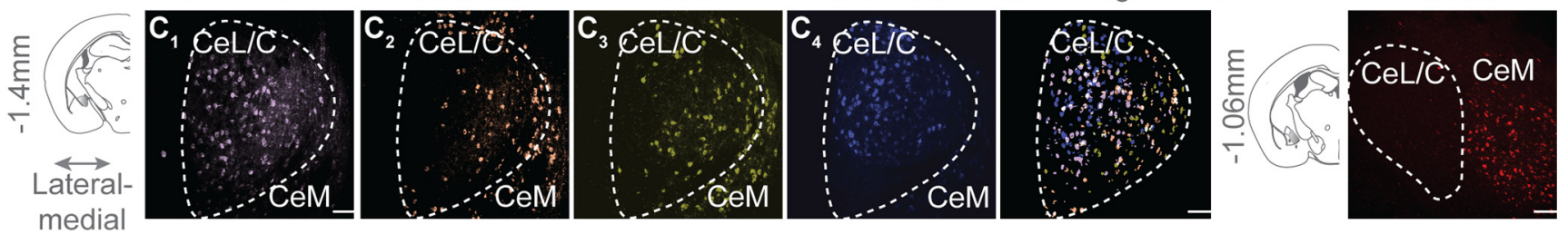

F
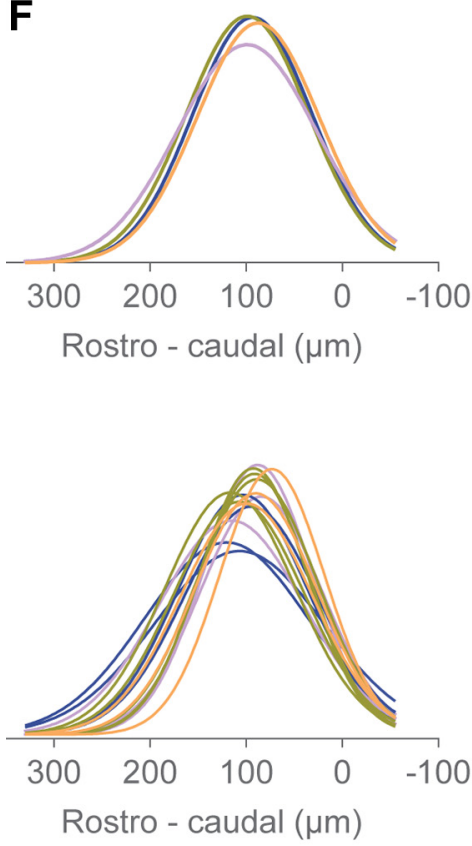

I

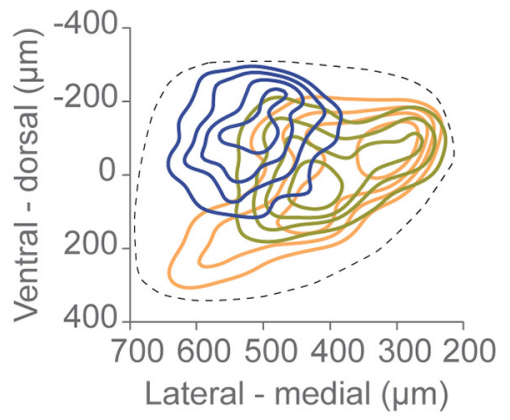

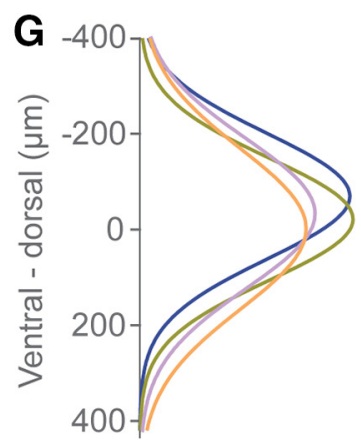
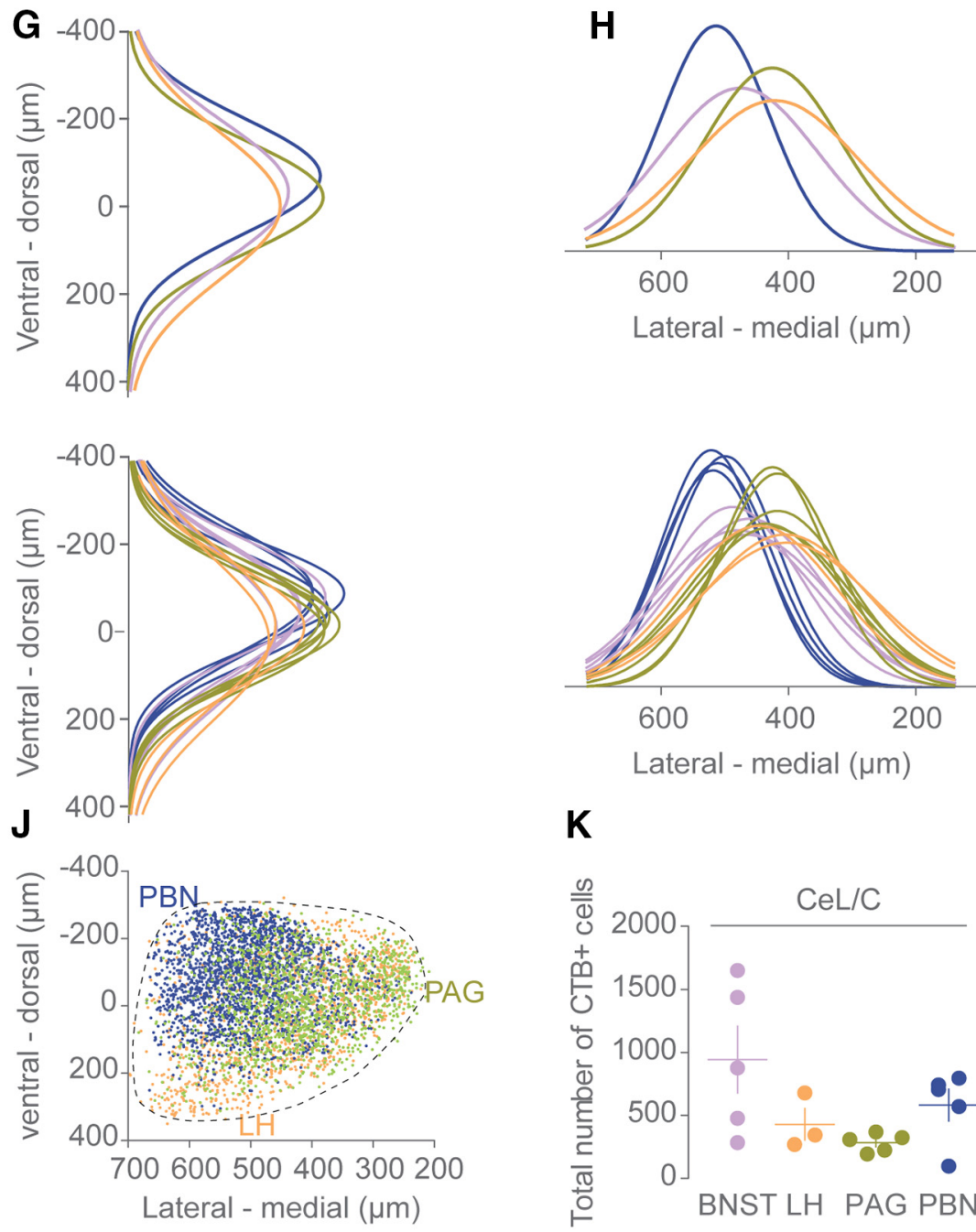

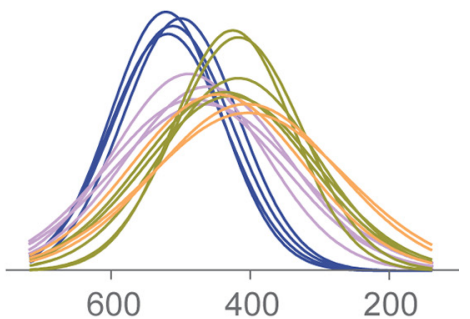

Lateral - medial $(\mu \mathrm{m})$

K

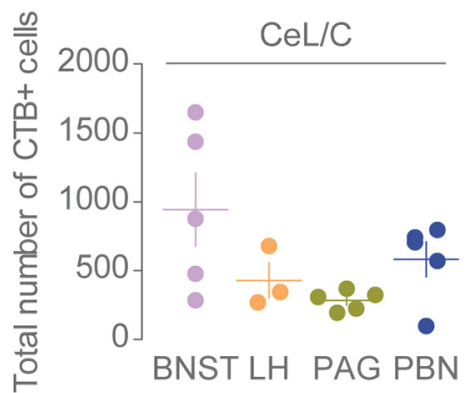

— BNST-proj. cells — LH-proj. cells —PAG-proj. cells — PBN-proj. cells

Figure 1. CeA projection neurons show spatial segregation. $\boldsymbol{A}$, Scheme illustrating the approach used to reveal spatial segregation among CeL/C projection neurons. Various $C \mathrm{CB}$ conjugates were injected into the BNST, LH, PAG or PBN of WT mice. $\boldsymbol{B}$, Representative epifluorescent images showing the location of the CTB injections in the BNST $\left(\boldsymbol{B}_{1}\right)$, LH $\left(\boldsymbol{B}_{2}\right)$, PAG $\left(\boldsymbol{B}_{3}\right)$, PBN $\left(\boldsymbol{B}_{4}\right)$, and IRN $\left(\boldsymbol{B}_{5}\right)$. Coronal section planes of a schematic brain are shown on top with distances (anterior-posterior axis) from bregma. ac: anterior commissure; fx: columns of the fornix; mtt: mammillothalamic tract; scp: superior cerebellar peduncles; VIIn: facial nerve. $\boldsymbol{C}$, Representative confocal images showing retrogradely labeled CTB+ cells in the CeL/C of WT mice injected in the 
PKC $\delta+$ cells $(25.4 \pm 2.7 \%$ of CTB + cells were immunopositive for PKC $\delta$ while $35.1 \pm 7.8 \%$ and $39.6 \pm 6.2 \%$ of CTB + cells were immunopositive for Htr2a-LacZ and Sst proteins, respectively; Fig. $2 \mathrm{~F}-\mathrm{H}$ ). Considering that Sst + and Htr2a+ neurons partially overlap, there may be contributions from other subpopulations to LH-projecting neurons that remain to be characterized.

Together, these results revealed distinct spatial arrangements, firing properties and molecular identities of $\mathrm{CeL} / \mathrm{C}$ projection neurons.

\section{A monosynaptic CeA connection between IC and LH}

To identify whether the IC preferentially targets one or several of the spatially segregated projection neuron subpopulations we employed the TRIO (Tracing the Relationship between Input and Output) method (Schwarz et al., 2015). Briefly, we used Credependent monosynaptic rabies tracing in the CeA where Cre expression was restricted to BNST-projecting, LH-projecting, PAG-projecting, or PBN-projecting CeA neurons. Cre expression was induced in these subpopulations by transducing their output regions with retrogradely transported canine adenovirus (CAV) and herpes simplex virus (HSV) viruses expressing the Cre recombinase (Fig. 3A). LH-projecting CeA neurons harbored the largest number of starter cells in the $\mathrm{CeL} / \mathrm{C}$, followed by tracings of BNST-projecting, PBN-projecting, and PAG-projecting CeA cells. (Fig. $3 B$ ). The relative proportions of the starter cells were somewhat different from the CTB tracings, possibly because of differences in tracing efficiency between the virus and CTB (Figs. $1 K, 3 B$ ). The spatial organization of starter cells, however, was quite similar to the one obtained with CTB tracings (Fig. 3C). Proportionally, LH-projecting and BNST-projecting starter cells were more abundant in the $\mathrm{CeL} / \mathrm{C}$, while PBN-projecting and PAG-projecting starters were more frequent in the CeM (Fig. 3D). Interestingly, the highest numbers of TRIO-labeled input neurons in the IC were observed for LH-projecting CeA neurons with a mean of 81 IC neurons per hemisphere/animal (Fig. $3 E-G$ ). This was in stark contrast to the results obtained for BNST-projecting, PAG-projecting, and PBN-projecting neurons, which yielded very few TRIO-labeled cells in the IC, suggesting that IC projections may preferentially target CeA projection neurons that send efferents to the LH. In the IC, inputs to LH-projecting CeA cells were particularly enriched

\section{$\leftarrow$}

BNST $\left(\boldsymbol{C}_{7}\right)$, LH $\left(\boldsymbol{C}_{2}\right)$, PAG $\left(\boldsymbol{C}_{3}\right)$, and/or PBN $\left(\boldsymbol{C}_{4}\right)$. The scheme on the left shows the location of the $\mathrm{CeL} / \mathrm{C}$ in a coronal section of a mouse brain (in gray, based on Paxinos and Franklin's atlas; Paxinos and Franklin, 2001). The value indicates the distance from bregma on the anterior-posterior axis. D, Corresponding digital reconstructions of BNST-projecting (violet), LHprojecting (orange), PAG-projecting (green) and PBN-projecting (blue) cell bodies (merge). $\boldsymbol{E}$, Representative confocal image (from three mice) showing retrogradely labeled CTB + cells in the CeM of WT mice injected in the IRN. $\boldsymbol{F}-\boldsymbol{H}$, Frequency distribution as percentage of BNSTprojecting (violet), LH-projecting (orange), PAG-projecting (green) and PBN-projecting (blue) neurons of the $\mathrm{CeL} / \mathrm{C}$ amygdala along the rostro-caudal $(\boldsymbol{F})$, dorso-ventral $(\boldsymbol{G})$, and lateralmedial $(\boldsymbol{H})$ axes. Graphs on top show the Gaussian fits of the average traces and bottom graphs show the single traces. I, Contour plots depicting Kernel density estimates of LH-projecting, PAG-projecting, and PBN-projecting neuron distributions along the lateral-medial and dorso-ventral axes. J, Digital coordinates along the lateral-medial and dorso-ventral axes of all reconstructed LH-projecting, PAG-projecting, and PBN-projecting CeA neurons. $\boldsymbol{K}$, Total numbers of retrogradely labeled CTB + cells in the CeL/C of WT mice injected in the BNST, LH, PAG, or PBN, as indicated. Quantifications and representative images from five BNST, three $L H$, five PAG, and five PBN injections. These injections represent a combination of several (TB injections per animal (see Materials and Methods). Bar graph shows means, and each dot is a separate experiment/animal. Scale bars of fluorescent images: $200 \mu \mathrm{m}(\boldsymbol{B})$ and $100 \mu \mathrm{m}(\boldsymbol{C}-\boldsymbol{E})$. between -0.5 and $+1 \mathrm{~mm}$ anterior-posterior to bregma, i.e., in the pIC (Fig. 3H,I), consistent with recently published work (Gehrlach et al., 2019).

\section{LH-projecting CeA cells are strongly activated by IC input}

To support our previous findings and quantify the probability of IC inputs to excite CeA projection neurons in vivo, we transduced the IC of WT mice with an AAV expressing Chr2 followed by an injection of conjugated CTB targeted to the BNST, LH, PAG or PBN. IC terminals in the CeA were then acutely photostimulated in vivo (Fig. $4 A$ ), and we subsequently analyzed immediate early gene expression (such as c-Fos) in both CTB + and CTB- cells. Using this strategy, we found that photostimulation of IC terminals triggered an increase in activity of $\mathrm{CeL} / \mathrm{C}$ neurons sufficient to induce expression of c-Fos (Fig. $4 B-F$ ). We observed that the largest fractions of c-Fos-positive neurons were identified as BNST-projecting and LH-projecting cells $(27.1 \%$ and $17.4 \%$, respectively; Fig. $4 G, H, K, L)$. Furthermore, CTB/c-Fos co-stained neurons accounted for $36.8 \%$ and $41.2 \%$ of the whole BNST-projecting and LH-projecting groups, respectively (Fig. $4 M, N)$. In contrast, only small fractions of c-Fos-positive neurons were identified as PAG-projecting or PBN-projecting cells (3.6\% and 8.6\%, respectively; Fig. $4 I-L$ ) and those CTB/c-Fos double-positive cells represented only a minor fraction of the whole PAG-projecting and PBN-projecting groups (Fig. 4M,N). These results suggest that large numbers of both BNST-projecting and LH-projecting cells were excited by IC inputs in vivo.

Next, we sought to assess the synaptic strength of IC inputs onto to the four CeA projection types. For this, we used a similar approach to the one described above, with the exception that Chr2-expressing IC axons were stimulated in brain slices (Petreanu et al., 2007). Such preparation allows the comparison of the amplitudes of EPSCs in CTB + versus CTB- cells (Fig. $5 A$ ). As expected for AMPAergic responses, photostimulation of glutamatergic IC terminals induced an inward current of the postsynaptic $\mathrm{CeA}$ neuron that can be blocked with NBQX, an AMPA receptor antagonist (Fig. 5B). In BNST-projecting, PAG-projecting, and PBN-projecting neurons, we detected short latency EPSCs in response to ChR2 photoexcitation but with significantly smaller amplitudes as compared with CTB-negative cells (Fig. 5C,G,E,I and F,J). Interestingly, the LH-projecting subpopulation was the only one to exhibit light-induced monosynaptic EPSCs that covered a wide range of amplitudes from lower to higher compared with CTB- neurons (Fig. 5D,H). This variation in amplitude is reflected in the coefficient of variation of $63 \%$ for $\mathrm{LH}$-projecting recordings versus $34 \%$ for controls.

We also recorded LH-projecting cells in current-clamp mode to assess the possibility of firing of these neurons after IC-axonal stimulations. The results showed that $\mathrm{LH}$-projecting cells were able to fire after consecutive stimulus ( $3 \mathrm{~ms}$ of blue light every 10 s) indicating that IC inputs have the ability to make LH-projecting cells fire. Responses of the neurons differed, however, with some neurons reaching firing threshold during all repetitive photostimulations and some neurons reaching firing threshold only sometimes (Fig. $5 K, L$ ).

In addition to monosynaptic excitation, we speculated that the IC might control effector cells via plurisynaptic inhibition from other inhibitory neurons in CeL/C. Indeed, several groups have reported reciprocal inhibitory interactions between defined cell types in the CeA (Ciocchi et al., 2010; Haubensak et al., 2010; Li et al., 2013; Douglass et al., 2017; Hunt et al., 2017). For LHprojecting and PBN-projecting cells, we detected similar IPSCs compared with CTB- cells (Fig. $5 N, R$ and $P, T$ ). For BNST- 

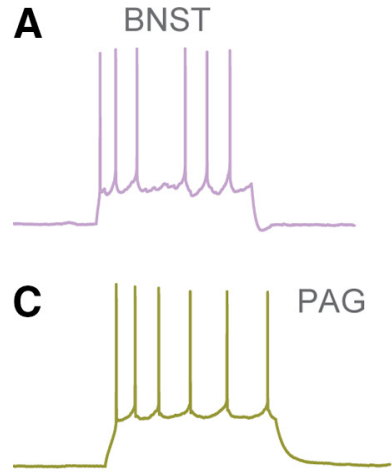
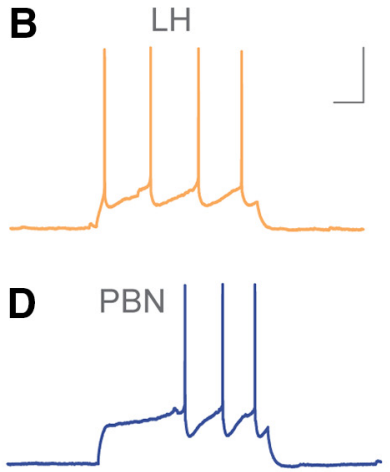

PKC $\mathrm{IHC}$

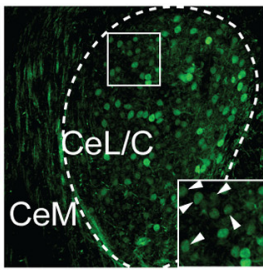

Htr2a-Lacz IHC

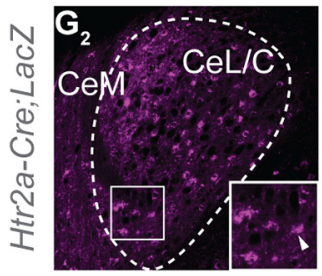

CTB BNST

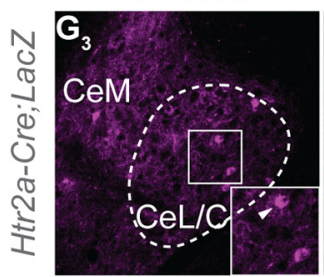

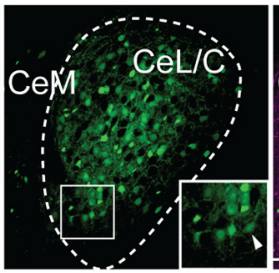

Sst IHC

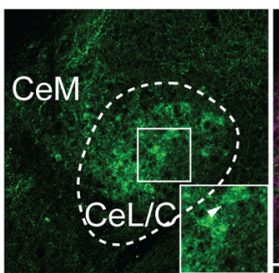

Merge

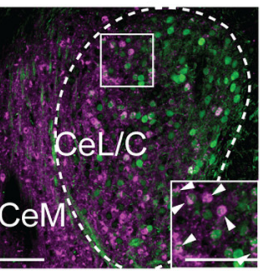

Merge

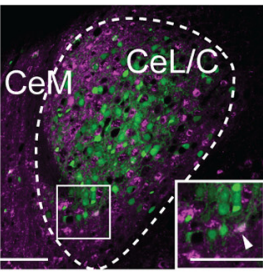

Merge

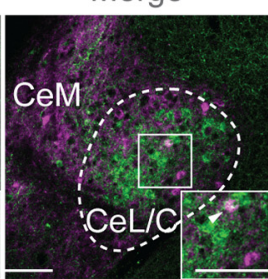

$\mathbf{E}$

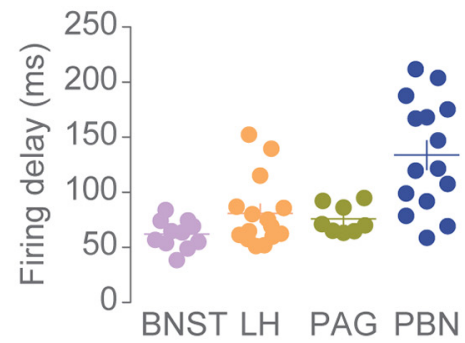

$\mathbf{F}$
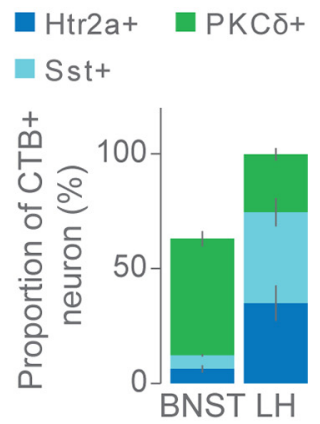
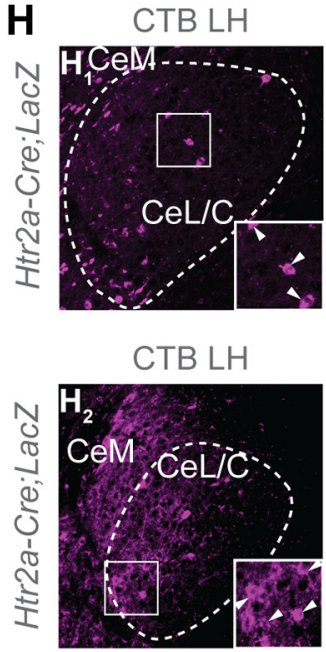

CTB LH

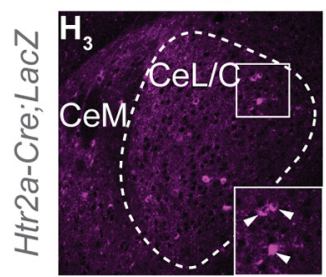

PKC IHC

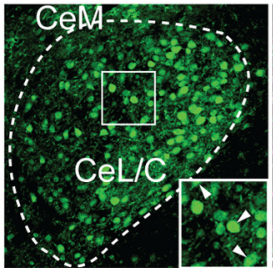

Htr2a-Lacz IHC

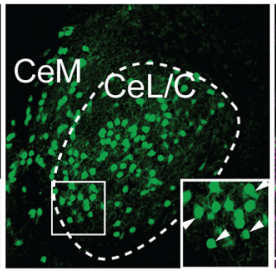

Sst IHC

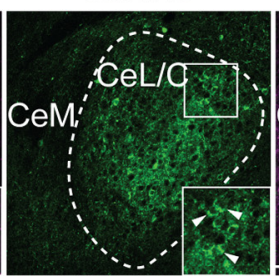

Merge

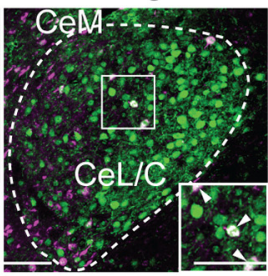

Merge

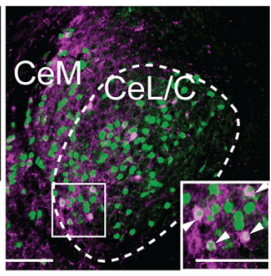

Merge

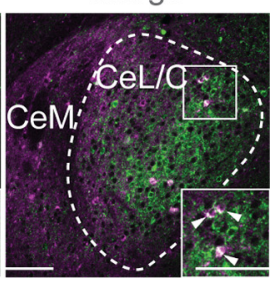

Figure 2. Electrophysiological and molecular properties of (eA projection neurons. $\boldsymbol{A}-\boldsymbol{D}$, Representative firing recordings of BNST-projecting ( $\boldsymbol{A}$, violet), LH-projecting ( $\boldsymbol{B}$, orange), PAG-projecting ( $\boldsymbol{C}$, green), and PBN-projecting ( $\boldsymbol{D}$, blue) neurons of the Cel/C amygdala in response to depolarizing currents of $1 \mathrm{~s}$, in whole-cell current-clamp recordings. $\boldsymbol{E}$, Quantification $(n=3$ mice per group) of the firing delay measured from the start of current injection to the start of the first action potential during the second current injection step in which an action potential is obtained. Graph shows mean \pm SEM, and each dot is a single-cell recording. Scale bar of electrophysiological recordings: $100 \mathrm{~ms}$ in the $x$-axis and $10 \mathrm{mV}$ in the $y$-axis. $\boldsymbol{F}$, Proportion of doublepositive immunostained/CTB cells among all CTB counted neurons in the CeL/C for BNST and LH traced brains; $n=3$ animals per condition. Graph shows mean \pm SEM. $\mathbf{G}, \boldsymbol{H}$, Representative confocal images showing the CeA of Htr2a-Cre;LacZ brains injected with retrogradely transported CTB in the BNST (G) and LH $(\boldsymbol{H})$ and immunostained for PKC $\delta\left(\boldsymbol{G}_{1}, \boldsymbol{H}_{\mathbf{1}}\right)$, LacZ $\left(\boldsymbol{G}_{\mathbf{2}}, \boldsymbol{H}_{\mathbf{2}}\right)$, and Sst $\left(\boldsymbol{G}_{3}, \boldsymbol{H}_{3}\right)$ proteins. The magnified view of the inset represents the area in the white box. Arrowheads indicate immunostained neurons co-labeled with CTB. Scale bars of fluorescent images: $100 \mu \mathrm{m}$.

projecting and PAG-projecting neurons however, the mean amplitude of the IPSCs was smaller compared with CTB- neurons (Fig. 5M,Q and $O, S$ ) indicating that they may receive less inhibitory currents from local CeA neurons on activation of IC inputs. We also examined paired-pulse ratios as an indicator of increased presynaptic release probability (Hess et al., 1987) but did not detect any differences between groups (Fig. $5 U-X$ ). In summary, our electrophysiological recordings together with the c-Fos data suggest that the IC sends disproportional inputs onto CeA projection neurons: while the IC contacts numerous LHprojecting CeA neurons with on average high strengths, IC connections onto BNST-projecting CeA cells were most frequent compared with other projection types, but weak in amplitude compared with controls.

\section{Discussion}

Previous studies have substantially extended our knowledge of differential inputs and outputs to molecularly defined CeA populations (Haubensak et al., 2010; Cai et al., 2014; Penzo et al., 2015; Douglass et al., 2017; Fadok et al., 2017; Kim et al., 2017; Schiff et al., 2018). However, additional work is needed to bridge the knowledge gap regarding the interaction between the two datasets. By mapping the direct relationship between the IC, a CeA sensory input region, and what we identified as the four main output projections of the CeL/C, our study sought to investigate how topdown information may be routed through and possibly computed locally within the CeA to give rise to scaled outputs.

Our data revealed a direct line of connection between the IC and the LH with a monosynaptic relay in the CeL/C. 
A

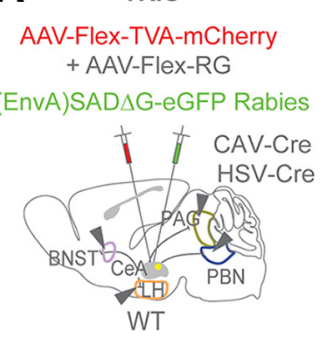

D

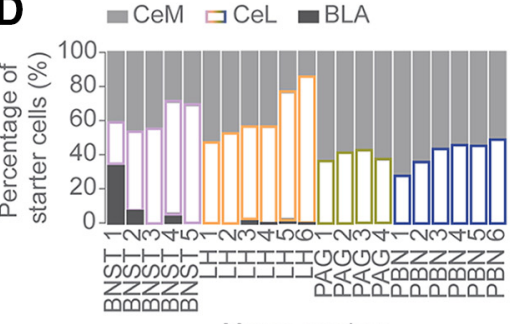

Mouse number

G

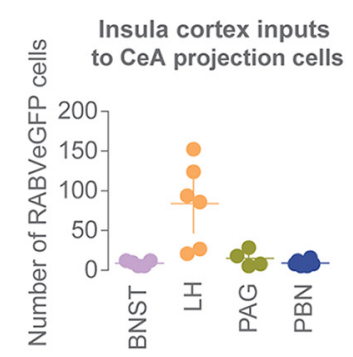

H

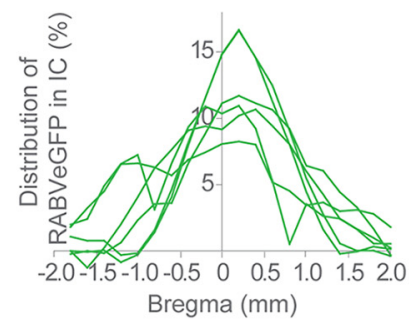

I

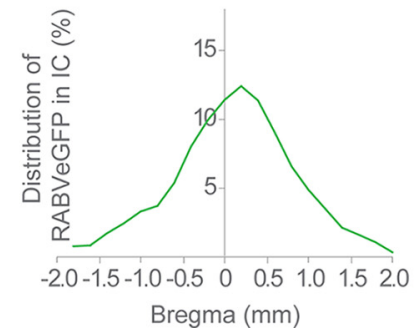

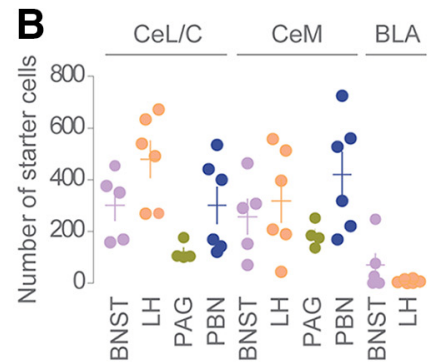

E

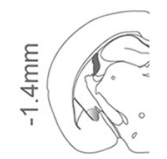

AAV helper-mcherry
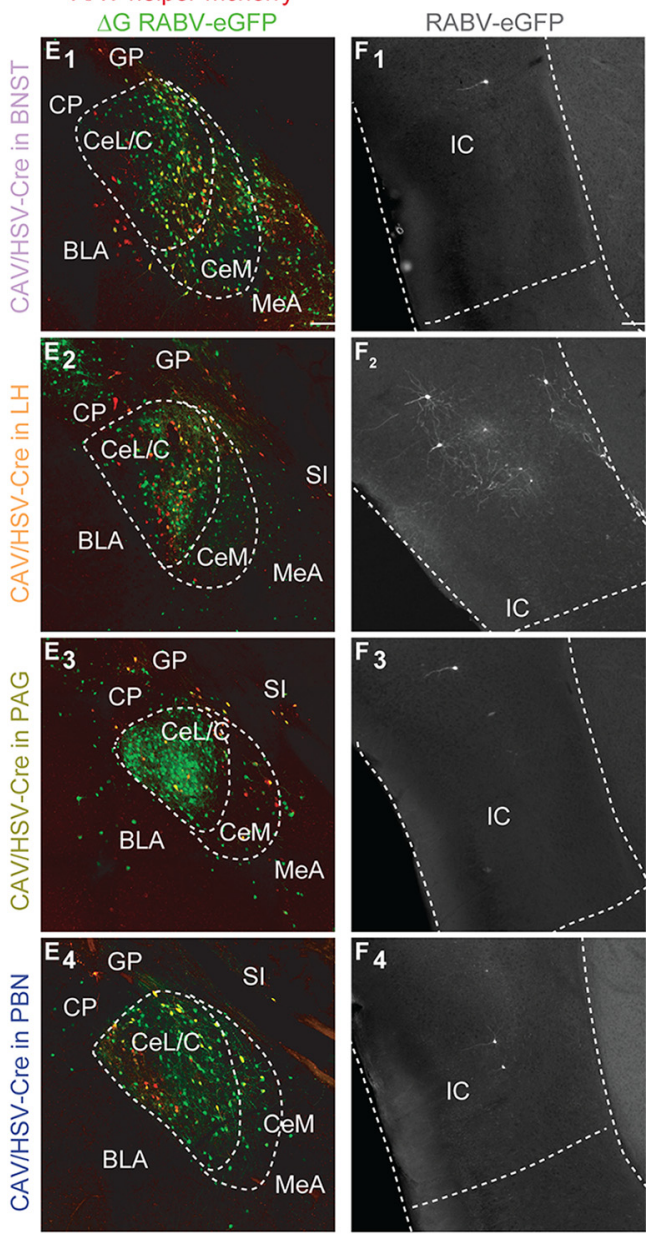

Figure 3. Monosynaptic CeA connection between IC and distinct CeA outputs. $A$, Scheme depicting the TRI0 strategy employed to reveal monosynaptic inputs to CeA projection neurons. The BNST, LH, PAG, or PBN of WT mice were transduced with retrogradely transported CAV and HSV viruses expressing Cre recombinase (Cav-Cre and HSV-Cre). Simultaneously, Cre-dependent helper adeno-associated viruses expressing the avian sarcoma leucosis virus glycoprotein EnvA receptor (TVA; AAV-FLEX-TVA-mCherry) and rabies virus envelope glycoprotein (RG; AAV-FLEX-RG) were injected in the CeA in combination with a modified rabies virus (EnvA)SAD $\triangle$ G-eGFP. B, Numbers of starter neurons in the CeL/C, CeM, and BLA of BNST-projecting, LH-projecting, PAG-projecting, and PBN-projecting CeA tracing experiments. C, Drawing based on Paxinos and Franklin's atlas of a coronal section through the CeL/C, CeM, and surrounding nuclei showing the approximate location of BNST-projecting, LH-projecting, PAG-projecting, and PBN-projecting CeA starter cells. BNST-projecting starters were found in CeA, BLA, MeA, and SI. LH-projecting starters were found in CeA, BLA, CP, GP, MeA, Sl, and LH. PAG-projecting starters were found in CeA, CP, GP, Sl, and LH. PBN-projecting starters were found in CeA, GP, and SI. D, Proportion of starter neurons in the Cel/C and CeM per tracing experiments. $\boldsymbol{E}_{\boldsymbol{E}}$ Representative confocal images of coronal sections through the CeA of BNST-projecting $\left(\boldsymbol{E}_{1}\right)$, LH-projecting $\left(\boldsymbol{E}_{2}\right)$, PAG-projecting $\left(\boldsymbol{E}_{3}\right)$, and PBN-projecting $\left(\boldsymbol{E}_{4}\right)$ CeAs. Coronal section plane of a schematic brain is shown on top with distance (anterior-posterior axis) from bregma. $\boldsymbol{F}$, Representative epifluorescent images of coronal sections showing the distribution of monosynaptic input cells (RABV-eGFP+ cells) to BNST-projecting $\left(\boldsymbol{F}_{7}\right)$, LH-projecting $\left(\boldsymbol{F}_{2}\right)$, PAG-projecting $\left(\boldsymbol{F}_{3}\right)$, and PBN-projecting $\left(\boldsymbol{F}_{4}\right)$ CeA neurons in the IC. Coronal section plane of a schematic brain is shown on $t$ with distance (anterior-posterior axis) from bregma. G, Total numbers of IC monosynaptic inputs to BNST-projecting, LH-projecting, PAG-projecting, and PBN-projecting CeA neurons. $\boldsymbol{H}, \boldsymbol{I}$, Frequency distribution along the rostro-caudal axis of RABV+ neurons in the IC of LH-projecting cells. $\boldsymbol{H}$ shows each quantified brain and $\boldsymbol{I}$ the average. Quantifications and representative images from five BNST, six LH, four PAG, and six PBN injections. Bar graphs show means, and each dot is a separate tracing experiment. Scale bars: $100 \mu \mathrm{m}$. globus pallidus (GP), caudate putamen (CP), substantia innominata (SI), medial amygdala (MeA). 
A

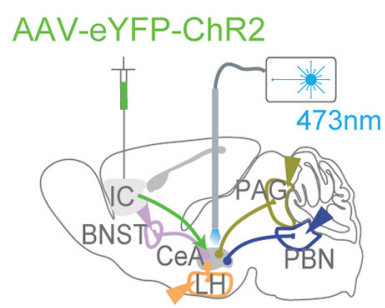

WT
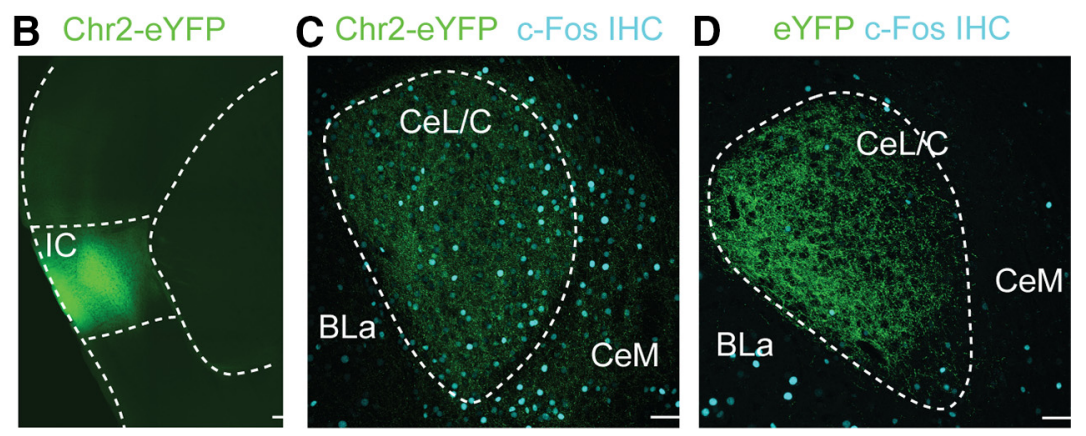

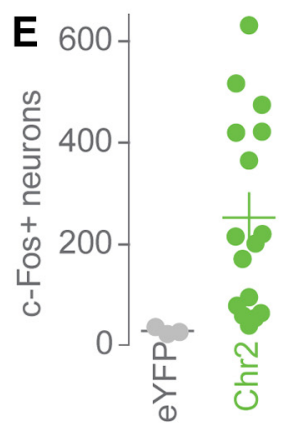

$\mathbf{F}$
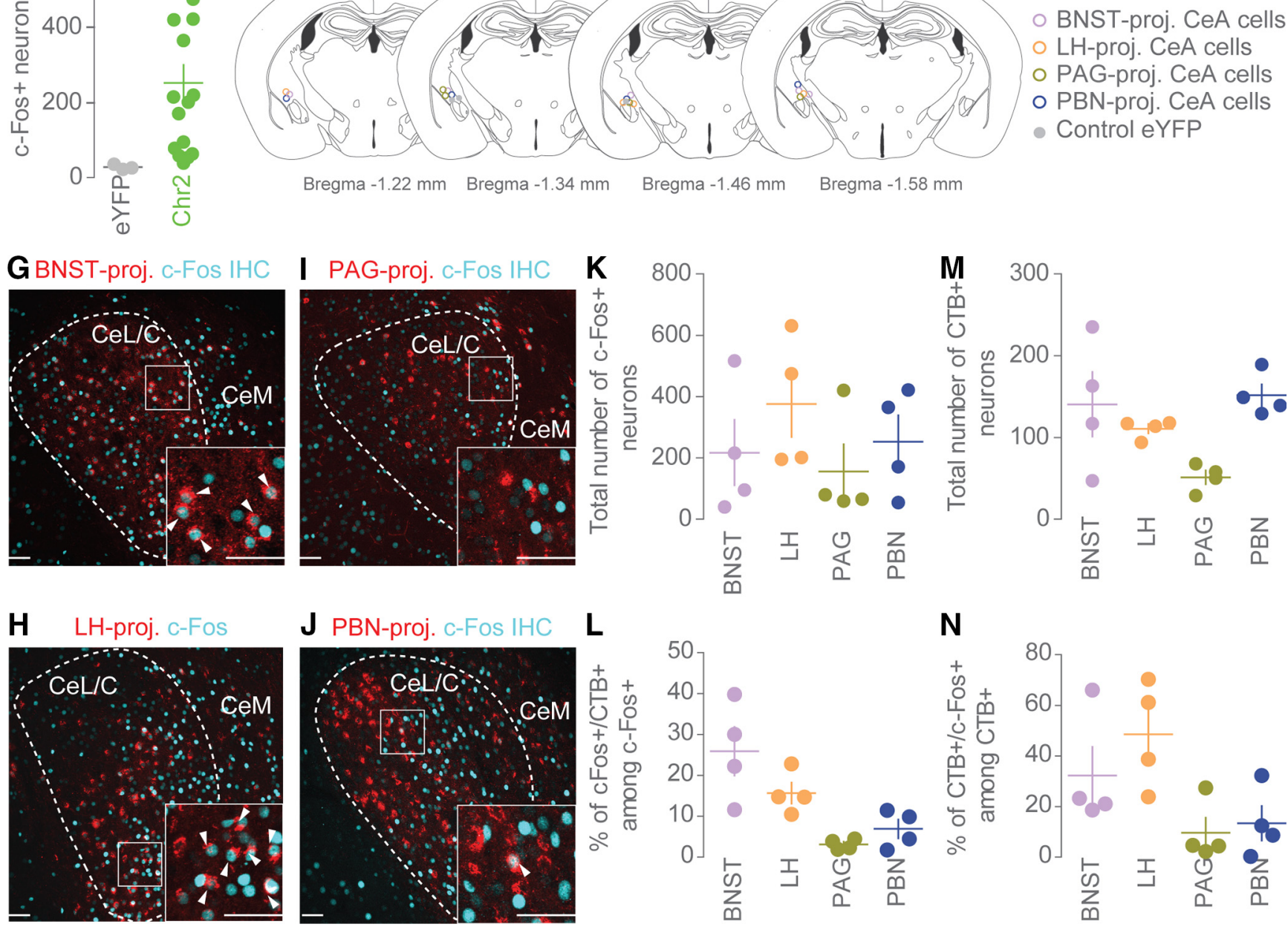

○ BNST-proj. CeA cells

o PAG-proj. CeA cells

O PBN-proj. CeA cells

Bregma -1.22 mm Bregma-1.34 mm Bregma -1.46 mm Bregma $-1.58 \mathrm{~mm}$

Figure 4. IC unevenly contacts CeA output streams. A, Scheme depicting the strategy used to identify in the CeA postsynaptic targets of IC neurons. The IC of WT mice was transduced with an AAV expressing Chr2-eYFP followed by injection of CTB conjugates in the BNST, or LH, or PAG, or PBN. Chr2-expressing IC axons were then photostimulated with blue light pulses in vivo through implanted optic fibers over the CeA. B, Representative epifluorescent image showing the expression of Chr2-eYFP in the IC of WT mice. C, D, Representative confocal image of a coronal section through the $\mathrm{CeA}$ of a photostimulated brain $(\boldsymbol{C})$ in which IC neurons were transduced with Chr2-eYFP and immunostained for $\mathrm{C}-\mathrm{Fos}$ and a control photostimulated brain (D) in which IC axons were transduced with eYFP only and immunostained for c-Fos. $\boldsymbol{E}$, Numbers of c-Fos + neurons in the CeA of 12 photostimulated mice in comparison to three photostimulated controls. $\boldsymbol{F}$, Approximate optic fiber locations for each animal. Locations are shown on schematic coronal section planes with distances (anterior-posterior axis) from bregma. G-J, Representative confocal images showing the CeA of photostimulated brains and injected with retrogradely transported CTB in the BNST $(\boldsymbol{G})$, LH $(\boldsymbol{H})$, PAG $(\boldsymbol{I})$, or PBN $(\boldsymbol{J})$. The magnified view of the inset represents the area in the white box. Arrowheads indicate c-Fos immunostained neurons co-labeled with CTB. $\boldsymbol{K}$, Total numbers of c-Fos + neurons per experiment. $\boldsymbol{L}$, Proportion of double-positive $c$-Fos/CTB cells among all c-Fos counted neurons in the CeL/C for BNST, LH, PAG, or PBN traced brains. $\boldsymbol{M}$, Total numbers of CTB + neurons per experiment. $\boldsymbol{N}$, Proportion of double-positive c-Fos/CTB cells among all CTB counted neurons in the CeL/C for BNST, LH, PAG, or PBN traced brains. Quantifications and representative images from four BNST, four LH, four PAG, and four PBN injections. Graphs show mean \pm SEM, and each dot is a separate experiment. Scale bars for confocal images: $100 \mu \mathrm{m}(\boldsymbol{B})$ and $50 \mu \mathrm{m}$ (all other images).

Importantly, we found that a subset of LH-projecting CeA cells were the most likely to be excited on activation of IC inputs to the CeA (Table 2). Both, in vivo optogenetic stimulation and ex vivo electrophysiological experiments showed that numerous
LH-projecting CeA neurons received strong inputs from the IC which can ultimately push these neurons to firing threshold. The TRIO strategy used to reveal monosynaptic inputs to CeA-projecting neurons revealed that $\mathrm{LH}$ projectors received larger 

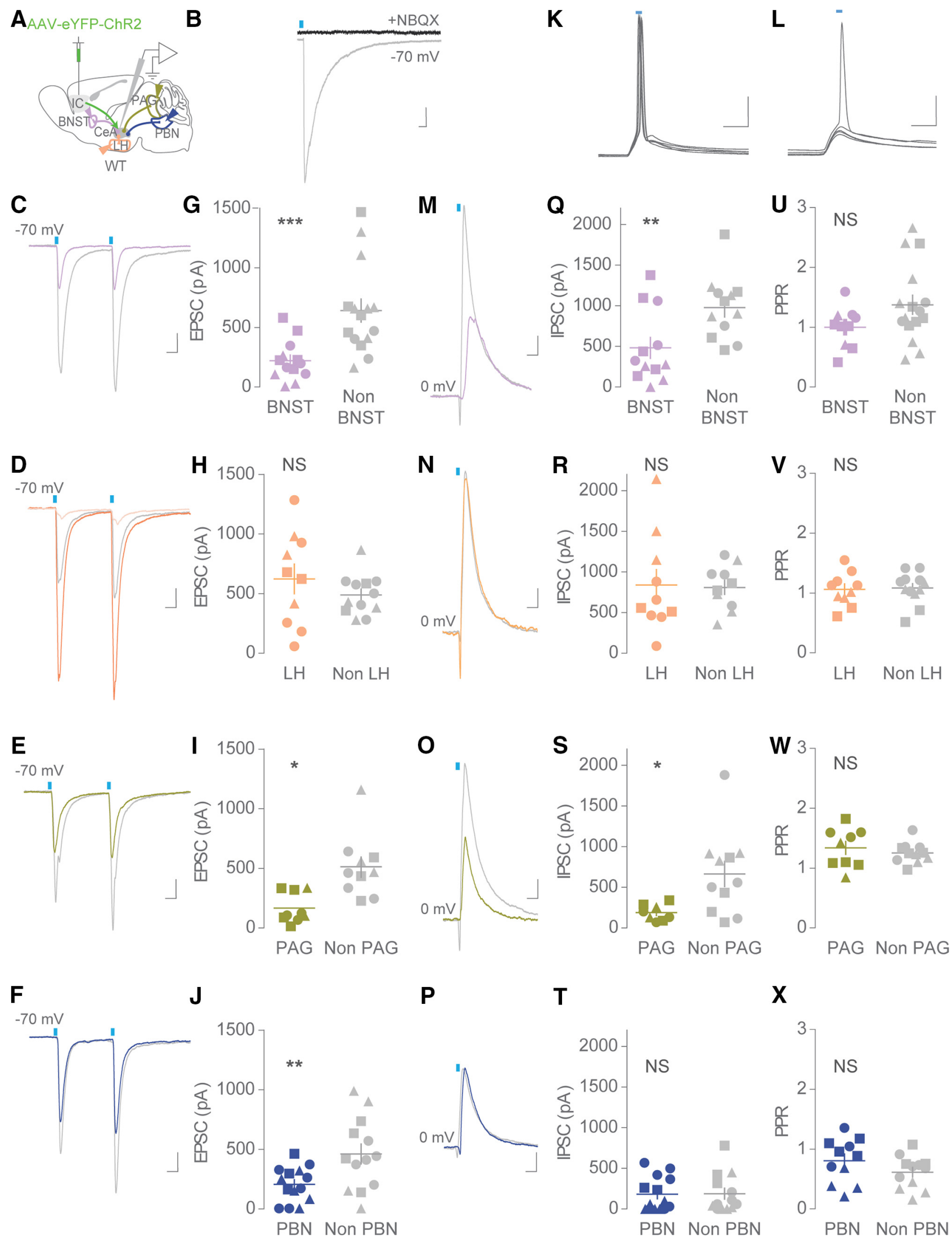

Figure 5. LH-projecting CeA cells are strongly activated by IC input. A, Scheme depicting the strategy used to identify in the CeA postsynaptic targets of IC neurons. The IC of WT mice was transduced with an AAV expressing Chr2-eYFP followed by injection of CTB conjugates in the BNST, or LH, or PAG, or PBN. Chr2-expressing IC axons were then photostimulated with blue light pulses in brain slices containing the CeA. $\boldsymbol{B}$, Representative EPSCs of a CeL/C neuron on IC-axonal excitation with blue light (blue bar). The monosynaptic glutamatergic response is blocked by NBQX (dark gray trace). $\mathbf{C}-\boldsymbol{F}$, Representative EPSCS of BNST-projecting ( $\boldsymbol{C}$, in violet), LH-projecting ( $\boldsymbol{D}$, in light orange for low-responding and dark orange for high-responding cells), PAG-projecting ( $\boldsymbol{E}$, in green), or PBN-projecting ( $\boldsymbol{F}$, in blue) cells, and (TB-negative (in gray) neurons on paired-pulses of blue light (blue bars). $\mathbf{G}-\boldsymbol{J}$, Quantifications of light-evoked responses (EPSC 
Table 2. Summary of findings

\begin{tabular}{|c|c|c|c|c|c|}
\hline CeA subpopulations & & LH-projecting & BNST-projecting & PAG-projecting & PBN-projecting \\
\hline Spatial location in CeL/C & & Medial & Uniform & Medial & Lateral \\
\hline Firing properties & & Mostly regular & Regular & Regular & Late to regular \\
\hline \multirow[t]{2}{*}{ Excitatory inputs from IC } & Number of RABV+ in IC & High & Low & Low & Low \\
\hline & EPSCs amplitude & Low to high & Low & Low & Low \\
\hline Inhibitory inputs from CeA on IC activation & IPSCS amplitude & No difference with ctrl & Low & Low & No difference with ctrl \\
\hline
\end{tabular}

Inputs from IC contact numerous BNST-projecting cells (colocalization with c-Fos is high) but are weak (EPSCs amplitude is low) which may explain a low number of RABV + cells following TRIO experiments. They are weakly inhibited by the local microcircuit on IC stimulation and are in general easily excitable (regular-spiking neurons), possibly explaining the high colocalization with c-Fos. Inputs from IC to LH-projecting neurons are numerous (colocalization with c-Fos and numbers of RABV + cells are high) and strong (EPSCs amplitude is high). PAG-projecting and PBN-projecting neurons overall receive low excitatory inputs from the IC (RABV experiments, c-Fos colocalization, ESPCs amplitude). PBN-projecting cells are additionally mostly late-firing and are segregated in the lateral part of the CeL/C suggesting that they may maintain connection with a different set of inputs.

number of inputs from the IC than PAG, PBN or BNST projectors. In addition, the majority of LH-projecting neurons were found to be regular-spiking consistent with the property of responding fast to incoming IC action potentials. Stimulation of IC inputs into the CeA has previously been shown to produce a panel of anxiety-related behaviors ranging from abrupt stopping or freezing, to backward escape movements (Gehrlach et al., 2019). The LH, on the other hand, has been traditionally described as a "feeding center" (Rossi and Stuber, 2018). Importantly, within the LH lies a population of GABAergic neurons whose acute inhibition reduces food intake and is aversive (Jennings et al., 2013; Navarro et al., 2016). It is therefore possible that the monosynaptic connection between IC and LH-projecting inhibitory CeA neurons contributes to the aversive phenotype described above. It would be of great interest to characterize the identity of those CeA neurons that integrate inputs from the IC, compare them to $\mathrm{LH}$ projecting $\mathrm{CeA}$ neurons, and thus understand which function they serve in this initially described IC-CeA pathway. One strategy would be to assess whether the aversive states observed during IC$\mathrm{CeA}$ stimulation are dampened when LH-projecting CeA neurons are silenced.

Although this direct connection alludes to a relative hardwiring of CeA circuits, it does not exclude that IC afferents may modulate other CeA outputs through different mechanisms. For instance, we found that a large fraction $(\sim 40 \%)$ of BNST-

$\leftarrow$

amplitudes) in voltage clamp $(-70 \mathrm{mV})$ of BNST-projecting $\left(\mathbf{G} ; n=3\right.$ mice, $t_{(26)}=3.710$, $p=0.0010)$, LH-projecting $\left(\boldsymbol{H} ; n=3\right.$ mice, $\left.t_{(20)}=1.080, p=0.2931\right)$, PAG-projecting $(\boldsymbol{I} ; n=$ 3 mice, $\left.t_{(17)}=3.554, p=0.024\right)$, or PBN-projecting $\left(J ; n=3\right.$ mice, $\left.t_{(25)}=2.830, p=0.0091\right)$ cells, compared with (TB-negative (in gray) neurons. $\boldsymbol{K}$, Representative current-clamp recordings of one LH-projecting CeA neuron reaching firing threshold during all five photostimulations of IC axons with blue light (blue bar, $3 \mathrm{~ms}$ ). $\boldsymbol{L}$, Representative current-clamp recordings of one LH-projecting CeA neuron reaching firing threshold only once out of five photostimulations of IC axons with blue light (blue bar, $3 \mathrm{~ms}$ ). $\boldsymbol{M}-\boldsymbol{P}$, Representative IPSCs of BNSTprojecting $(\boldsymbol{M}$, in violet), LH-projecting ( $\boldsymbol{N}$, in orange), PAG-projecting $(\boldsymbol{0}$, in green), or PBN-projecting ( $\boldsymbol{P}$, in blue) cells, and (TB-negative (in gray) neurons on paired-pulses of blue light (blue bars). Q- $\boldsymbol{T}$, Quantification of light-evoked responses (mean IPSC amplitude) in voltage clamp of BNST-projecting $\left(\boldsymbol{Q} ; n=3\right.$ mice, $\left.t_{(26)}=2.880, p=0.0087\right)$, LH-projecting $\left(\boldsymbol{R} ; n=3\right.$ mice, $\left.t_{(20)}=0.1371, p=0.8924\right)$, PAG-projecting $\left(S ; n=3\right.$ mice, $t_{(17)}=2.555$, $p=0.0205)$, or PBN-projecting $\left(\boldsymbol{T} ; n=3\right.$ mice, $\left.t_{(25)}=0.09,471, p=0.9253\right)$ cells, compared with CTB-negative (in gray) neurons. $\boldsymbol{U}-\boldsymbol{X}$, Quantification of PPR in BNST-projecting ( $\boldsymbol{U}$; $n=3$ mice, $\left.t_{(24)}=1.690, p=0.1040\right)$, LH-projecting $\left(\boldsymbol{V} ; n=3\right.$ mice, $t_{(20)}=0.1820$, $p=0.8924)$, PAG-projecting ( $\boldsymbol{W} ; n=3$ mice, $\left.t_{(18)}=0.7372, p=0.8674\right)$, and PBN-projecting $\left(X ; n=3\right.$ mice, $\left.t_{(14)}=0.8113, p=0.4308\right)$ cells compared with (TB negative (in gray) neurons. Graphs show the amplitude mean $\pm \mathrm{SEM}$, and each symbol is a single-cell recording. Identical symbols represent cells recorded from one animal. Two-tailed unpaired $t$ test; $* p<0.05, * * p<0.01, * * * p<0.001$. Scale bars for electrophysiological recordings in $\boldsymbol{K}, \boldsymbol{L}: 20 \mathrm{mV}$ in the $y$-axis and $5 \mathrm{~ms}$ in the $x$-axis. Scale bars for all the other electrophysiological recordings: $100 \mathrm{pA}$ in the $y$-axis and $10 \mathrm{~ms}$ in the $x$-axis. projecting cells expressed c-Fos after IC axon stimulation (Table 2). This result is in contrast to the TRIO tracing method which revealed only few RABV + neurons in the IC following tracing of BNST-projecting CeA cells (Table 2). Our electrophysiological recordings indicated that the strength of this excitatory connection is relatively weak (Table 2), raising the possibility that RABV may not "jump" weak synapses very efficiently, but rather has a bias toward propagating through "strong" synapses. BNSTprojecting neurons seem to also be less affected by concomitant inhibition from the local CeA circuits and display rapid onset firing properties, which may further explain the observed increase in c-Fos expression in this population. Hence, the IC-BNST connection may be a target for learning-induced synaptic potentiation, and BNST-projecting CeA neurons may form stimulusvalence associations necessary for the formation of aversive memories, which is consistent with a role for $\mathrm{CeL} / \mathrm{C}$ during learning (Fadok et al., 2018).

Alternatively, beyond the direct monosynaptic connections investigated in this study, local computations may also be instrumental in the control of CeA afferents. As the CeA is exclusively composed of GABAergic cells, we could imagine a three synapse diagram involving first, "encoding" CeA neurons that receive direct inputs from the IC; second, an intermediate population of local interneurons, and third, the projection cells, which are all connected in a similar manner to what has been previously described (Ciocchi et al., 2010). In this model, under baseline conditions, the intermediate population inhibits the projection neurons. However, IC activation of encoding cells, leads to disinhibition of the intermediate ones, therefore releasing tonic inhibition onto the output neurons. In this layout, excitation of projection neurons would be facilitated by external components, such as neuromodulators and homeostatic and experience-dependent signals could for instance instruct CeA circuits with the appropriate behavioral programs.

Our ex vivo electrophysiological recordings revealed that most recorded neurons and regardless of their output targets, received at least some inputs from the IC, although c-Fos labeling was in comparison relatively sparse. One possibility is that in an in vivo setting where all axons are preserved, di-synaptic inhibition may play a greater role and prevent firing of the neuron as well as subsequent expression of c-Fos. This emphasizes again the importance of understanding the local connections within the CeA microcircuit.

Our data revealed that projection neurons belong to distinct firing types adding an additional layer to the complexity of communication within this network. The firing onset could heighten asymmetry in the connectivity, with for instance LH and BNSTprojecting cells responding fast to IC stimulation, therefore inhibiting other projection neurons. At a more global level, 
projection cells that differ in their firing properties may be more responsive to particular input frequencies, a property that may reflect distinct way of communication with the output targets. Additionally, our data uncovered a topographical arrangement of $\mathrm{CeL} / \mathrm{C}$ output streamlines which we believe may aid the microcircuit to correctly interpret the wide range of inputs transmitted to the CeA, and thus be central to the dynamics of this network.

Previous work has provided a wealth of information on the function of genetically distinct cell types in the CeA. Sst-expressing cells have been reported to be the main source of efferents to the brainstem including PAG and PBN (Magableh and Lundy, 2014; Penzo et al., 2014; Douglass et al., 2017; Kim et al., 2017; Ye and Veinante, 2019). Instead, we found that the BNST in the forebrain receives strong projections from $\mathrm{PKC} \delta$-positive neurons (see also Ye and Veinante, 2019), while the LH receives input from PKC $\delta$-positive, Htr2a-positive, and Sst-positive neurons in somewhat similar proportions. Further delineation of IC inputs onto CeA cell populations, based on both their molecular profiles and output pattern, will be required to understand how IC inputs come to affect behavior.

In conclusion, the present data advance our knowledge of long-range inputs and outputs of CeA circuit organization and support a model in which the CeA is a collective of collaborative neuronal circuits acting together to coordinate pleasant or unpleasant behaviors depending on the environmental conditions and the internal state of the animal. Considering all the projecting neuronal subpopulations evaluated here with different techniques, neurons of the CeA that project to the $\mathrm{LH}$ are the ones that receive the strongest inputs from the IC, and could be relevant for future behavioral analyses while PAG-projecting and $\mathrm{PBN}$-projecting groups are the least likely to be affected by monosynaptic excitation from the IC (Table 2).

\section{References}

Cai H, Haubensak W, Anthony TE, Anderson DJ (2014) Central amygdala PKC- $\delta+$ neurons mediate the influence of multiple anorexigenic signals. Nat Neurosci 17:1240-1248.

Carter ME, Soden ME, Zweifel LS, Palmiter RD (2013) Genetic identification of a neural circuit that suppresses appetite. Nature 503:111-114.

Chieng BCH, Christie MJ, Osborne PB (2006) Characterization of neurons in the rat central nucleus of the amygdala: cellular physiology, morphology, and opioid sensitivity. J Comp Neurol 497:910-927.

Ciocchi S, Herry C, Grenier F, Wolff SBE, Letzkus JJ, Vlachos I, Ehrlich I, Sprengel R, Deisseroth K, Stadler MB, Müller C, Lüthi A (2010) Encoding of conditioned fear in central amygdala inhibitory circuits. Nature 468:277-282.

Corbit LH, Balleine BW (2005) Double dissociation of basolateral and central amygdala lesions on the general and outcome-specific forms of pavlovian-instrumental transfer. J Neurosci 25:962-970.

Douglass AM, Kucukdereli H, Ponserre M, Markovic M, Gründemann J, Strobel C, Alcala Morales PL, Conzelmann KK, Lüthi A, Klein R (2017) Central amygdala circuits modulate food consumption through a positive-valence mechanism. Nat Neurosci 20:1384-1394.

Ehrlich I, Humeau Y, Grenier F, Ciocchi S, Herry C, Lüthi A (2009) Amygdala inhibitory circuits and the control of fear memory. Neuron 62:757-771.

Fadok JP, Krabbe S, Markovic M, Courtin J, Xu C, Massi L, Botta P, Bylund K, Müller C, Kovacevic A, Tovote P, Lüthi A (2017) A competitive inhibitory circuit for selection of active and passive fear responses. Nature 542:96-99.

Fadok JP, Markovic M, Tovote P, Lüthi A (2018) New perspectives on central amygdala function. Curr Opin Neurobiol 49:141-147.

Gallagher M, Graham PW, Holland PC, Graham WP, Holland PC, Graham PW (1990) The amygdala central nucleus and appetitive Pavlovian conditioning: lesions impair one class of conditioned behavior. J. Neurosci 10:1906-1911.
Gehrlach DA, Dolensek N, Klein AS, Roy Chowdhury R, Matthys A, Junghänel M, Gaitanos TN, Podgornik A, Black TD, Reddy Vaka N, Conzelmann KK, Gogolla N (2019) Aversive state processing in the posterior insular cortex. Nat Neurosci 22:1424-1437.

Gu Y, Piper WT, Branigan LA, Vazey EM, Aston-Jones G, Lin L, LeDoux JE, Sears RM (2020) A brainstem-central amygdala circuit underlies defensive responses to learned threats. Mol Psychiatry 25:640-654.

Han S, Soleiman M, Soden M, Zweifel L, Palmiter RD (2015) Elucidating an affective pain circuit that creates a threat memory. Cell 162:363-374.

Haubensak W, Kunwar PS, Cai H, Ciocchi S, Wall NR, Ponnusamy R, Biag J, Dong HW, Deisseroth K, Callaway EM, Fanselow MS, Lüthi A, Anderson DJ (2010) Genetic dissection of an amygdala microcircuit that gates conditioned fear. Nature 468:270-276.

Hess G, Kuhnt U, Voronin LL (1987) Quantal analysis of paired-pulse facilitation in guinea pig hippocampal slices. Neurosci Lett 77:187-192.

Hunt S, Sun Y, Kucukdereli H, Klein R, Sah P (2017) Intrinsic circuits in the lateral central amygdala. eNeuro 4.

Jennings JH, Rizzi G, Stamatakis AM, Ung RL, Stuber GD (2013) The inhibitory circuit architecture of the lateral hypothalamus orchestrates feeding. Science 341:1517-1521.

Khalsa SS, Adolphs R, Cameron OG, Critchley HD, Davenport PW, Feinstein JS, Feusner JD, Garfinkel SN, Lane RD, Mehling WE, Meuret AE, Nemeroff CB, Oppenheimer S, Petzschner FH, Pollatos O, Rhudy JL, Schramm LP, Simmons WK, Stein MB, Stephan KE, et al. (2018) Interoception and mental health: a roadmap. Biol Psychiatry Cogn Neurosci Neuroimaging 3:501-513.

Killcross S, Robbins TW, Everitt BJ (1997) Different types of fear-conditioned behaviour mediated by separate nuclei within amygdala. Nature 388:377-380.

Kim J, Zhang X, Muralidhar S, LeBlanc SA, Tonegawa S (2017) Basolateral to central amygdala neural circuits for appetitive behaviors. Neuron 93:1464-1479.

Knobloch HS, Charlet A, Hoffmann LC, Eliava M, Khrulev S, Cetin AH, Osten P, Schwarz MK, Seeburg PH, Stoop R, Grinevich V (2012) Evoked axonal oxytocin release in the central amygdala attenuates fear response. Neuron 73:553-566.

LeDoux JE, Iwata J, Cicchetti P, Reis DJ (1988) Different projections of the central amygdaloid nucleus mediate autonomic and behavioral correlates of conditioned fear. J Neurosci 8:2517-2529.

Lein ES, Hawrylycz MJ, Ao N, Ayres M, Bensinger A, Bernard A, Boe AF, Boguski MS, Brockway KS, Byrnes EJ, Chen L, Chen L, Chen TM, Chin MC, Chong J, Crook BE, Czaplinska A, Dang CN, Datta S, Dee NR, et al. (2007) Genome-wide atlas of gene expression in the adult mouse brain. Nature 445:168-176.

Li H, Penzo MA, Taniguchi H, Kopec CD, Huang ZJ, Li B (2013) Experience-dependent modification of a central amygdala fear circuit. Nat Neurosci 16:332-339.

Livneh Y, Ramesh RN, Burgess CR, Levandowski KM, Madara JC, Fenselau H, Goldey GJ, Diaz VE, Jikomes N, Resch JM, Lowell BB, Andermann ML (2017) Homeostatic circuits selectively gate food cue responses in insular cortex. Nature 546:611-616.

Livneh Y, Sugden AU, Madara JC, Essner RA, Flores VI, Sugden LA, Resch JM, Lowell BB, Andermann ML (2020) Estimation of current and future physiological states in insular cortex. Neuron 105:1094-1111.e10.

Magableh A, Lundy R (2014) Somatostatin and corticotrophin releasing hormone cell types are a major source of descending input from the forebrain to the parabrachial nucleus in mice. Chem Senses 39:673-682.

McDonald AJ, Shammah-Lagnado SJ, Shi C, Davis M (1999) Cortical afferents to the extended amygdala. Ann NY Acad Sci 877:309-338.

Navarro M, Olney JJ, Burnham NW, Mazzone CM, Lowery-Gionta EG, Pleil KE, Kash TL, Thiele TE (2016) Lateral hypothalamus GABAergic neurons modulate consummatory behaviors regardless of the caloric content or biological relevance of the consumed stimuli. Neuropsychopharmacology 41:1505-1512.

Parkinson JA, Robbins TW, Everitt BJ (2000) Dissociable roles of the central and basolateral amygdala in appetitive emotional learning. Eur J Neurosci 12:405-413.

Paxinos G, Franklin KBJ (2001) The mouse brain in stereotaxic coordinates, Ed 2. San Diego: Academic Press.

Penzo MA, Robert V, Li B (2014) Fear conditioning potentiates synaptic transmission onto long-range projection neurons in the lateral subdivision of central amygdala. J Neurosci 34:2432-2437. 
Penzo MA, Robert V, Tucciarone J, De Bundel D, Wang M, Van Aelst L, Darvas M, Parada LF, Palmiter RD, He M, Huang ZJ, Li B (2015) The paraventricular thalamus controls a central amygdala fear circuit. Nature 519:455-459.

Petreanu L, Huber D, Sobczyk A, Svoboda K (2007) Channelrhodopsin-2assisted circuit mapping of long-range callosal projections. Nat Neurosci 10:663-668.

Rossi MA, Stuber GD (2018) Overlapping brain circuits for homeostatic and hedonic feeding. Cell Metab 27:42-56.

Sah P, Faber ESL, De Armentia ML, Power J (2003) The amygdaloid complex: anatomy and physiology. Physiol Rev 83:803-834.

Sanford CA, Soden ME, Baird MA, Miller SM, Schulkin J, Palmiter RD, Clark M, Zweifel LS (2017) A central amygdala CRF circuit facilitates learning about weak threats. Neuron 93:164-178.

Schiff HC, Bouhuis AL, Yu K, Penzo MA, Li H, He M, Li B (2018) An insulacentral amygdala circuit for guiding tastant-reinforced choice behavior. J Neurosci 38:1418-1429.

Schwarz LA, Miyamichi K, Gao XJ, Beier KT, Weissbourd B, Deloach KE, Ren J, Ibanes S, Malenka RC, Kremer EJ, Luo L (2015) Viral-genetic tracing of the input-output organization of a central noradrenaline circuit. Nature 524:88-92.

Shi CJ, Cassell MD (1998) Cortical, thalamic, and amygdaloid connections of the anterior and posterior insular cortices. J Comp Neurol 399:440-468.

Soriano P (1999) Generalized lacZ expression with the ROSA26 Cre reporter strain. Nat Genet 21:70-71.
Swanson LW, Petrovich GD (1998) What is the amygdala? Trends Neurosci 21:323-331.

Tye KM, Prakash R, Kim SY, Fenno LE, Grosenick L, Zarabi H, Thompson KR, Gradinaru V, Ramakrishnan C, Deisseroth K (2011) Amygdala circuitry mediating reversible and bidirectional control of anxiety. Nature 471:358-362.

Veinante P, Yalcin I, Barrot M (2013) The amygdala between sensation and affect: a role in pain. J Mol Psychiatry 1:9.

Viviani D, Charlet A, Van Den Burg E, Robinet C, Hurni N, Abatis M, Magara F, Stoop R (2011) Oxytocin selectively gates fear responses through distinct outputs from the central amygdala. Science 333:104-107.

Wang L, Gillis-Smith S, Peng Y, Zhang J, Chen X, Salzman CD, Ryba NJP, Zuker CS (2018) The coding of valence and identity in the mammalian taste system. Nature 558:127-131.

Wickersham IR, Lyon DC, Barnard RJO, Mori T, Finke S, Conzelmann KK, Young JAT, Callaway EM (2007) Monosynaptic restriction of transsynaptic tracing from single, genetically targeted neurons. Neuron 53:639647.

Xu C, Krabbe S, Gründemann J, Botta P, Fadok JP, Osakada F, Saur D, Grewe BF, Schnitzer MJ, Callaway EM, Lüthi A (2016) Distinct hippocampal pathways mediate dissociable roles of context in memory retrieval. Cell 167:961-972.e16.

Ye J, Veinante P (2019) Cell-type specific parallel circuits in the bed nucleus of the stria terminalis and the central nucleus of the amygdala of the mouse. Brain Struct Funct 224:1067-1095. 